\title{
Fabrication and Analysis of Polydimethylsiloxane (PDMS) Microchannels for Biomedical Application
}

\author{
Shahzadi Tayyaba ${ }^{1}$, Muhammad Waseem Ashraf ${ }^{2, *}$, Zubair Ahmad ${ }^{3, * \mathbb{C}}$, Ning Wang ${ }^{4}$, \\ Muhammad Javaid Afzal ${ }^{5}$ (D) and Nitin Afzulpurkar 6 \\ 1 Department of Computer Engineering, University of Lahore, Lahore 54000, Pakistan; \\ shahzadi.tayyaba@hotmail.com or Shahzadi.Tayyaba@dce.uol.edu.pk \\ 2 Department of Physics (Electronics), GC University, Lahore 54000, Pakistan \\ 3 Center for Advanced Material (CAM), Qatar University, Doha P.O. Box 2713, Qatar \\ 4 Center for Green Innovation, School of Mathematics and Physics, University of Science and Technology \\ Beijing, Beijing 100069, China, wangning@ustb.edu.cn \\ 5 Department of Physics, Govt. Islamia College Civil Lines, Lahore 54000, Pakistan; javaidphy@gmail.com \\ 6 Department of Mechanical Engineering Technology (MCET), Higher Colleges of Technology (HCT), \\ Ras al-Khaimah P.O. Box 4793, UAE; afzulpurkar.n@gmail.com \\ * Correspondence: dr.waseem@gcu.edu.pk (M.W.A.); zubairtarar@qu.edu.qa (Z.A.)
}

check for updates

Citation: Tayyaba, S.; Ashraf, M.W.; Ahmad, Z.; Wang, N.; Afzal, M.J.; Afzulpurkar, N. Fabrication and Analysis of Polydimethylsiloxane (PDMS) Microchannels for Biomedical Application. Processes 2021, 9, 57. https://doi.org/10.3390/ pr9010057

Received: 24 March 2020

Accepted: 29 May 2020

Published: 29 December 2020

Publisher's Note: MDPI stays neutral with regard to jurisdictional claims in published maps and institutional affiliations.

Copyright: () 2020 by the authors. Licensee MDPI, Basel, Switzerland. This article is an open access article distributed under the terms and conditions of the Creative Commons Attribution (CC BY) license (https: / / creativecommons.org/ licenses/by/4.0/).

\begin{abstract}
In this research work, Polydimethylsiloxane (PDMS) has been used for the fabrication of microchannels for biomedical application. Under the internet of things (IoT)-based controlled environment, the authors have simulated and fabricated bio-endurable, biocompatible and bioengineered PDMS-based microchannels for varicose veins implantation exclusively to avoid tissue damaging. Five curved ascending curvilinear micro-channel (5CACMC) and five curved descending curvilinear micro-channels (5CDCMC) are simulated by MATLAB (The Math-Works, Natick, MA, USA) and ANSYS (ANSYS, The University of Lahore, Pakistan) with actual environments and confirmed experimentally. The total length of each channel is $1.6 \mathrm{~cm}$. The diameter of both channels is $400 \mu \mathrm{m}$. In the ascending channel, the first to fifth curve cycles have the radii of $2.5 \mathrm{~mm}, 5 \mathrm{~mm}, 7.5 \mathrm{~mm}$, $10 \mathrm{~mm}$, and $2.5 \mathrm{~mm}$ respectively. In the descending channel, the first and second curve cycles have the radii of $12.5 \mathrm{~mm}$ and $10 \mathrm{~mm}$ respectively. The third to fifth cycles have the radii of $7.5 \mathrm{~mm}$, $5 \mathrm{~mm}$, and $2.5 \mathrm{~mm}$ respectively. For 5CACMC, at Reynolds number of 185, the values of the flow rates, velocities and pressure drops are $19.7 \mu \mathrm{Ls}^{-1}, 0.105 \mathrm{~mm} / \mathrm{s}$ and $1.18 \mathrm{~Pa}$ for Fuzzy simulation, $19.3 \mu \mathrm{Ls}^{-1}, 0.1543 \mathrm{~mm} / \mathrm{s}$ and 1.6 Pa for ANSYS simulation and $18.23 \mu \mathrm{Ls}^{-1}, 0.1332 \mathrm{~mm} / \mathrm{s}$ and $1.5 \mathrm{~Pa}$ in the experiment. For 5CDCMC, at Reynolds number 143, the values of the flow rates, velocities and pressure drops are $15.4 \mu \mathrm{Ls}^{-1}, 0.1032 \mathrm{~mm} / \mathrm{s}$ and $1.15 \mathrm{~Pa}$ for Fuzzy simulation, $15.0 \mu \mathrm{Ls}^{-1}$, $0.120 \mathrm{~mm} / \mathrm{s}$ and $1.22 \mathrm{~Pa}$ for ANSYS simulation and $14.08 \mu \mathrm{Ls}^{-1}, 0.105 \mathrm{~mm} / \mathrm{s}$ and $1.18 \mathrm{~Pa}$ in the experiment. Both channels have three inputs and one output. In order to observe Dean Flow, Dean numbers are also calculated. Therefore, both PDMS channels can be implanted in place of varicose veins to have natural blood flow.
\end{abstract}

Keywords: internet of things (IoT); curvilinear microchannel; polydimethylsiloxane (PDMS); sterilization; biocompatibility; fuzzy

\section{Introduction}

Internet of things (IoT) has been potentially used to develop miniaturized devices. Various parameters have been controlled using IoT during the process level fabrication. These miniaturized devices are used in different fields. IoT plays a significant role in advancement of microfluidic devices. Diverse parameters of microfluidic devices like fluid flow time, temperature, flow rate, flow velocity, pressure drop, density and viscosity can be monitored and examined using IoT devices. These devices can be used potentially for analysis and detection for specific applications [1-4]. The schematic of IoT controlled microfluidic system is shown in Figure 1. 


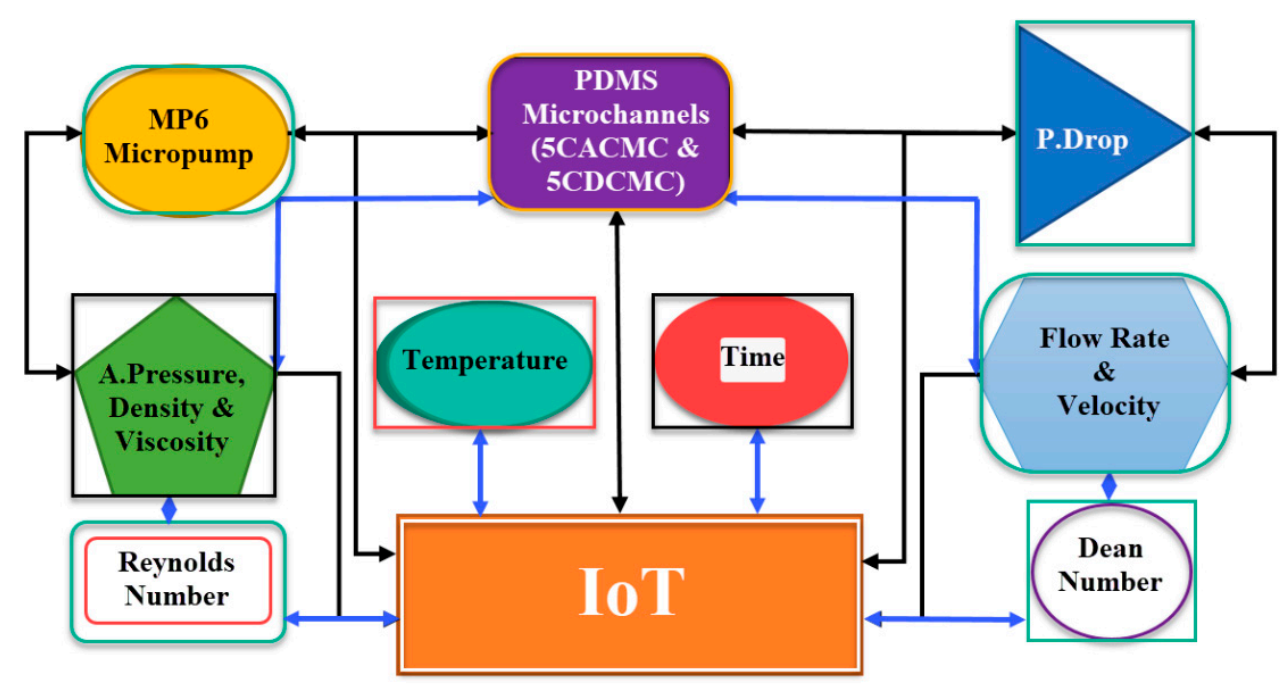

Figure 1. Internet of things (IoT) Controlled Microfluidic System.

Nowadays, polymer-based implantable devices like bioengineered veins, plates of bone, dental parts, muscles, discs of vertebral, valves of heart, and pacemakers are used in biomedical engineering to reinstate the damaged organs $[5,6]$. Polymer-based biomaterials can provide assistance for the healing process in the human body. The polymer materials are utilized mostly due to adaptability, structure, properties, and treatment methods. These biomaterials can be utilized in various compositions like solids, films, gels, and fibers for treatment and analysis in several biomedical applications [7-12]. Every implant in the human body must be done accurately for the proper functions of cells, tissues, and fluids. The biomaterial used for surgical implants must be biocompatible [13-15]. The core purpose of the present work is to engineer and evaluate the use of PDMS microchannels as a potential replacement for varicose veins. These bioengineered veins must promote a better blood flow and avoid tissue-damaging [16].

PDMS can be considered as the functional material for implantations in various biomedical applications like joints, nasal bones, other bones, teeth, sutures, blood tubes, spine and hearts $[17,18]$. All biomaterials used in implantations have fundamental properties for long term usage in the body [19]. Metals, composites, polymers, and ceramics can be used separately and in combination for the development of these implantations. These implantations should be developed and implanted very carefully, so that these may not result into issues like cancer, immunogenicity, teratogenicity and toxicity. These materials must have high mechanical properties and corrosion resistance. The common biomaterials are polymeric biomaterials, synthetic polymers, naturally occurring polymers, polyvinylchloride, polyethylene, polypropylene, polymethylmetacrylate, polyurethane, polyethersulfone, polyetherimide, polyamide, polystyrene, polytetrafluoroethylene, polyethylenterephthalate, composite biomaterials and ceramic biomaterials [20-22]. Their usage has been given in Table 1. 
Table 1. Biomaterials and their usage.

\begin{tabular}{ll}
\hline \multicolumn{1}{c}{ Biomaterial } & \multicolumn{1}{c}{ Usage } \\
\hline Synthetic polymers [23] & Encompasses water-repelling materials \\
\hline Naturally occurring polymers [24] & Blood purification, dental-related problems \\
\hline Polyvinylchloride [25] & The bag containing blood and solutions \\
\hline Polyethylene [26] & Bone related implants \\
\hline Polypropylene [27] & Disposed syringes, artificial vascular grafts. \\
\hline Polymethylmethacrylate [28] & Making pumps used to pump blood and reservoirs \\
\hline Polystyrene [29] & $\begin{array}{l}\text { Making filter devices (bladder regeneration) and flasks used } \\
\text { for tissue culture }\end{array}$ \\
\hline Polytetrafluoroethylene [30] & $\begin{array}{l}\text { Making Catheter and artificial vascular grafts (diaphragm } \\
\text { regeneration) }\end{array}$ \\
\hline Polyurethane [31] & Making films used for packaging (pancreas regeneration) \\
\hline Polyamide [32] & Sutures and molds \\
\hline Polyethylene terephthalate [33] & Making Implantable sutures and heart valve \\
\hline Polyethersulfone [34] & Catheters and Lumen tubing \\
\hline Polyetherimide [35] & Skin staplers used in surgery \\
\hline Composite biomaterials [36] & Filling teeth, bone cement \\
\hline Ceramic biomaterials [37] & $\begin{array}{l}\text { Muscular systems and skeletal systems are repaired and } \\
\text { replaced }\end{array}$ \\
\hline
\end{tabular}

Three-dimensional (3D) printing technology has been used to design a wearable electronic system based on IoT to determine the health monitoring system [38]. Qualitative research has been done to investigate the various designs of microchannels that have been reported with the application of IoT. In this decade, IoT devices have been widely used for 3D printing [39,40]. IoT has also been reported for the development of automatic microfluidic system [41].

In our previous papers, the authors fabricated silver bio-engineered veins for varicose vein implantation. The previous studies have some limitations like biocompatibility, elasticity and friction $[42,43]$. Here, in this research, the authors have tried to overcome the limitations of biocompatibility, flexibility and resistance. Therefore, the PDMS has been used to fabricate the microchannels for varicose vein implantation. This polymer is naturally flexible, biocompatible and exhibits less friction with the flow speed $[16,44,45]$. These polymer channels can be implanted to avoid tissue-damaging effect after the removal of varicose veins. There is a wide use of microchannels in biomedical engineering and other fields [46-51].

\subsection{Sterilization and Toxicity of Polymeric Implants}

The sterilization can be explained as a procedure by which organisms, germs, bacteria and other contaminated cells are eliminated from the implanted device. Aseptic processing and terminal sterilization can be used for contamination removal $[52,53]$. The most common and economical method is the terminal sterilization to reduce the threat of infection. It is essential to sterilize these bio-medical transplants and surgical implant before use to decrease the danger of contaminations and related impediments. The standard sterilization methods are applying radioactive rays, steam spray, heat or a mixture of these techniques and $\gamma$-radiations [54]. Possible toxic impurities can be transferred in these devices through handling, cleansing, storing, packing and transportation. Allergy, haemolysis, toxicity, thrombosis, carcinogenicity, eye-tissue irritation, and pyrogenicity can be caused due to contaminated polymeric devices [55]. PDMS-based devices are prone to less contamination [56,57]. 


\subsection{Surgical Polymeric Implants (PDMS)}

PDMS is used for the expansion and beauty of the cheeks, breast, nasal, and jawbones [7]. It has been extensively acknowledged by specialists for the humanoid bone extension due to its variable rigidity, molding, shaping capability and ease of use. It has not been reported in literature that PDMS implantations has caused any infection in connective tissues that leads PDMS is very safe to use for implants $[6,13,15,58,59]$. PDMS has been used for facial implantations, stomach wall infection treatment, retinal implants, tendons and ligaments surgeries, breast implantations and expansion, spine surgery, cardiac and vascular muscles, knee treatment and replacement and rat implantations [60-70]. Some PDMS implant investigations are listed in Table 2.

Table 2. Polydimethylsiloxane (PDMS) Implants.

\begin{tabular}{ccc}
\hline Reference & PDMS Implant & Cause \\
\hline Siproudhis et al. [60] & Elastomer & Faecal incontinence \\
\hline Losi et al. [61] & Abdominal & Intestinal infections \\
\hline Tunc et al. [62] & Retinal & Retina bleeding \\
\hline Franca et al. [65] & Breast & Low weight \\
\hline Suchy et al. [66] & Spine & Spine Cage repair \\
\hline Lim et al. [67] & Cartilage & Low regeneration \\
\hline Kuo et al. [63] & Ligament & Regenerative strategies \\
\hline Zhang et al. [69] & Vascular & Cardiac arrest \\
\hline
\end{tabular}

The authors have proposed a PDMS-based bioengineered vein to implant as varicose vein. Human blood has been used for extensive investigations in this research. The viscosity of human blood is averagely taken as $0.0032 \mathrm{Kg} / \mathrm{ms}$ [71]. Viscosity and density of blood can exhibit a strong effect on the blood flow rate in veins. Blood volume and its mass have been used as the traditional method for blood density measurement. It is related to the hematocrit of blood. Blood density is different in young, old, males, and females. Blood density of young females is less than adult females while blood density of young males is less than adults. The density of blood in females is less than males. This is because the red cells of young males and females have a higher negative charge than the adults. Therefore, the mobility of blood cells is higher in young people $[52,53,55,56]$. Females have more blood flow than the male because of increased rate of pumping of their heart [72]. The human blood density differs from person to person due to blood count changes and other factors. The venous blood and arterial blood differ in density. The venous blood density seems to change even with the change in the posture of the body. In this study, blood (plasma) density is considered $1025 \mathrm{~kg} / \mathrm{m}^{3}$ and blood (cells) density is taken as $1125 \mathrm{kgm}^{-3}$ [44,57]. Typically, the blood density for humans (female and male) is taken as $1060 \mathrm{kgm}^{-3}[16,45]$. Some possible PDMS-based implants in humans depending on the requirement have been shown in Figure 2.

The authors have simulated two types of microchannels using MATLAB and ANSYS. First one is five curved ascending curvilinear microchannels (5CACMC) and the second one is five curved descending curvilinear microchannels (5CDCMC). After the simulation, the fabrication of the channels has been performed. Then these channels have been tested using actual human blood. This research work may provide new way of PDMS-based varicose vein implantation. 


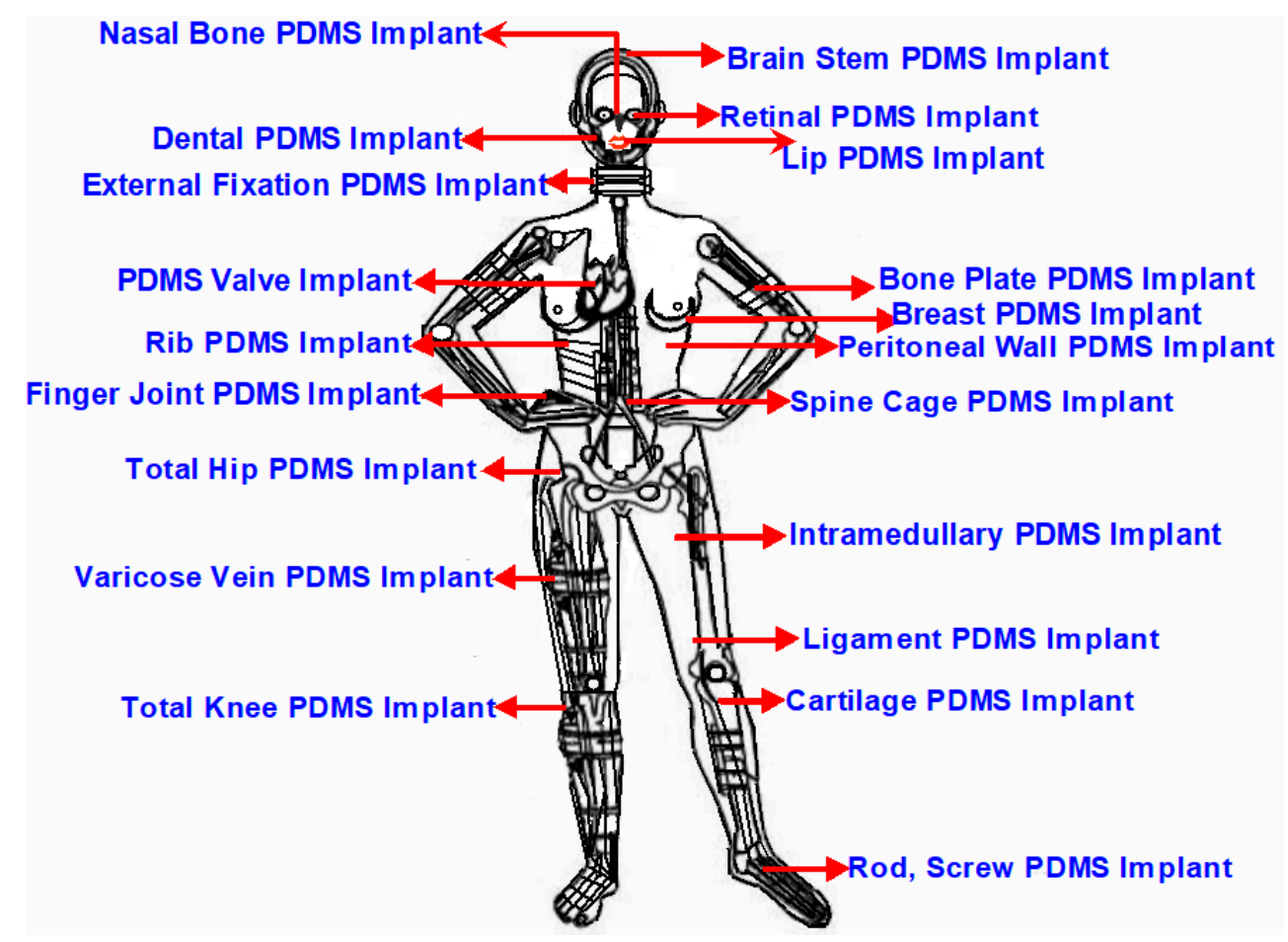

Figure 2. Possible PDMS-based Implants in the human body.

\section{Fuzzy Logic Simulation for 5CACMC and 5CDCMC}

Fuzzy simulation is extensively used in almost every field of research [73-77]. In this simulation, two fuzzy systems for 5CACMC and 5CDCMC have been developed with four inputs and three outputs. The inputs are Reynolds Number, applied pressure, viscosity and density. The outputs are flow rate, velocity and pressure drop. All have three membership functions. The ranges are 0 to 200 for Reynolds number, 1 to $1.5 \mathrm{Kilo} \mathrm{Pa}$ for applied pressure, 0.003 to $0.004 \mathrm{Kgm}^{-1} \mathrm{~s}^{-1}$ for viscosity, 925 to $1125 \mathrm{Kgm}^{-3}$ for blood density, 15 to $25 \mu \mathrm{Ls}^{-1}$ for flow rate, 0.01 to $0.2 \mathrm{mms}^{-1}$ velocity and 0.2 to $2 \mathrm{~Pa}$ for pressure drop. For simulation, eighty-one rules were prepared with If-AND-THEN statements. The rule viewers in MATLAB are shown below in Figure 3a,b for both 5CACMC and 5CDCMC.

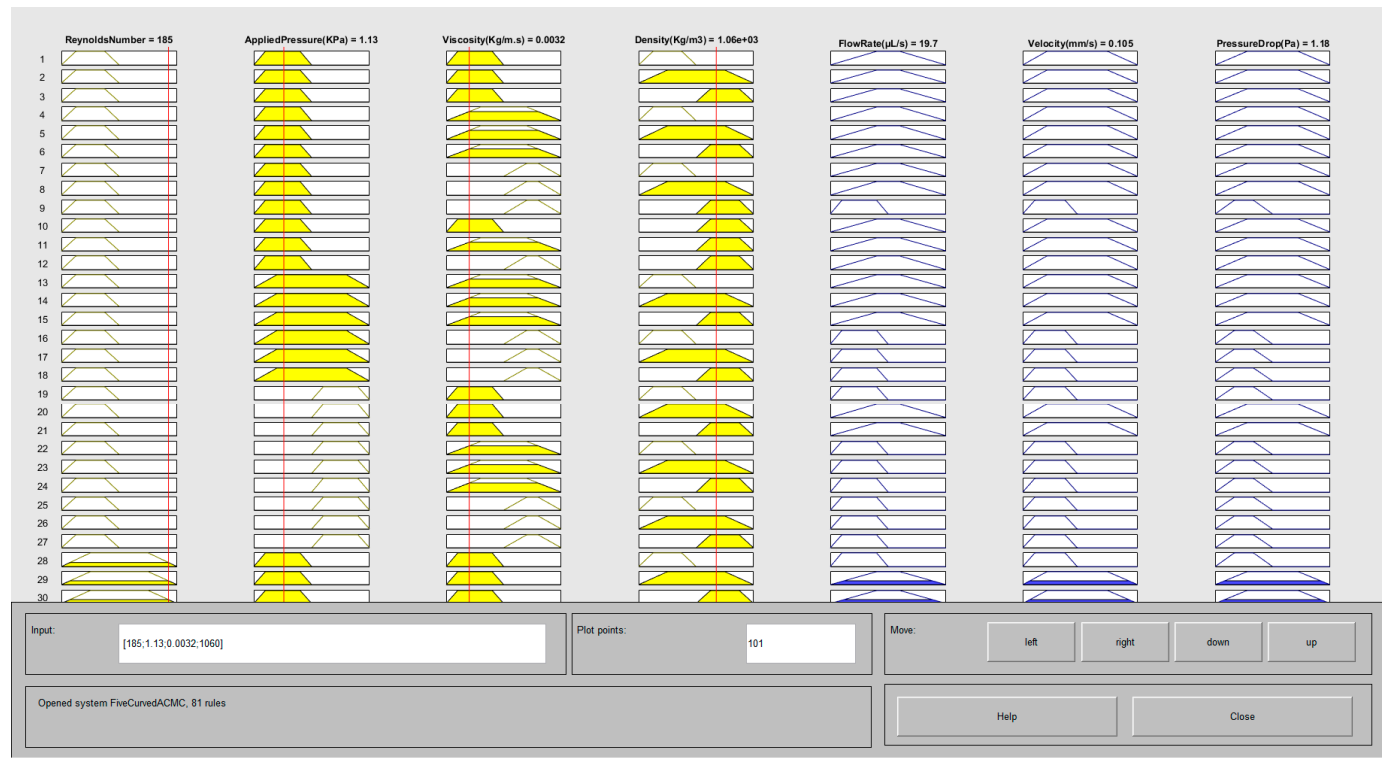

(a)

Figure 3. Cont. 


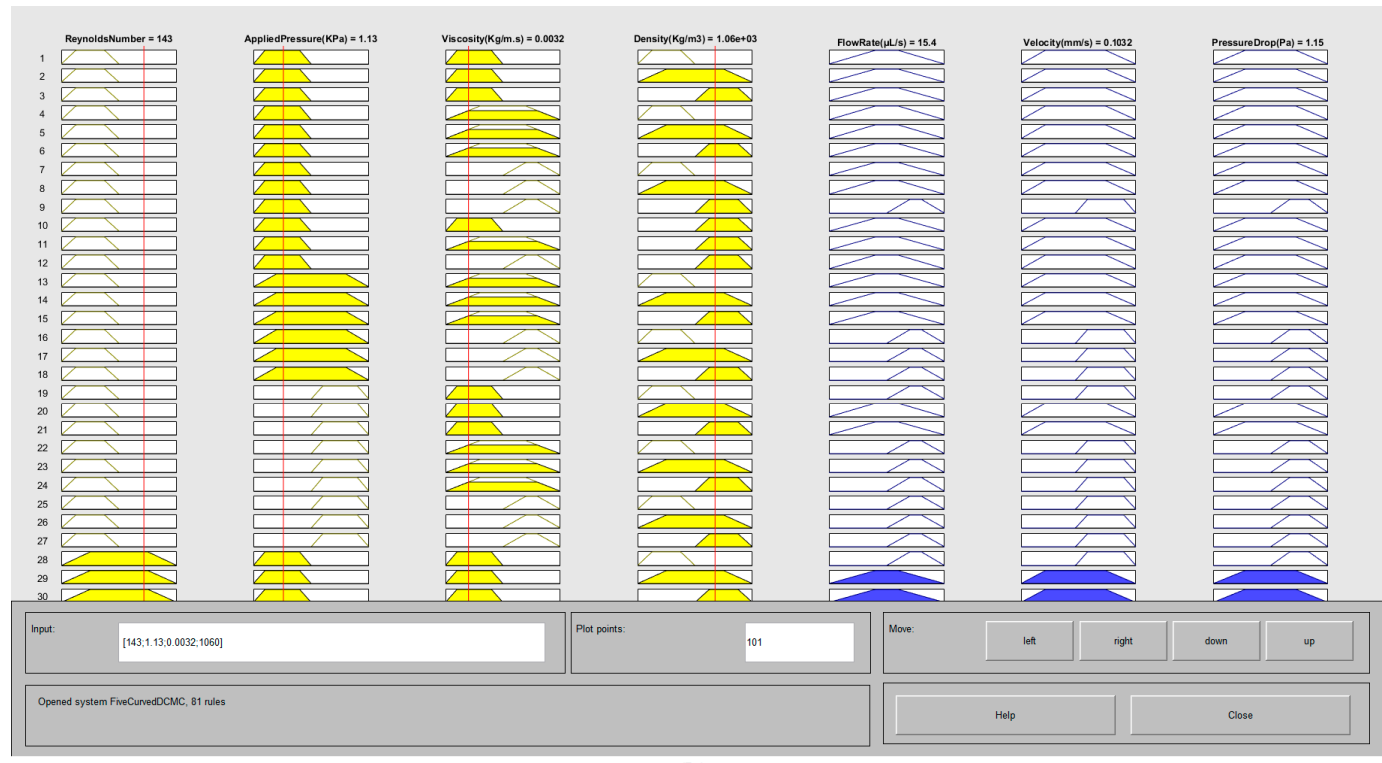

(b)

Figure 3. Rule viewer (a) For five curved ascending curvilinear micro-channel (5CACMC) (b) For five curved descending curvilinear micro-channels (5CDCMC).

After the simulation, the three-dimensional graphs obtained for 5CACMC from Fuzzy logic simulation with flow rate as output are shown below in Figure 4.

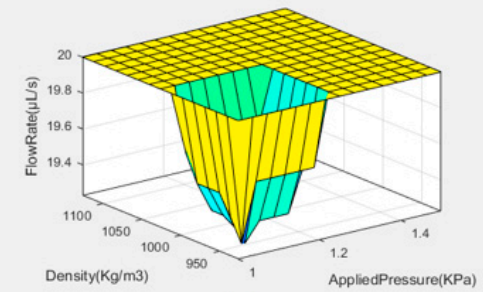

(a)

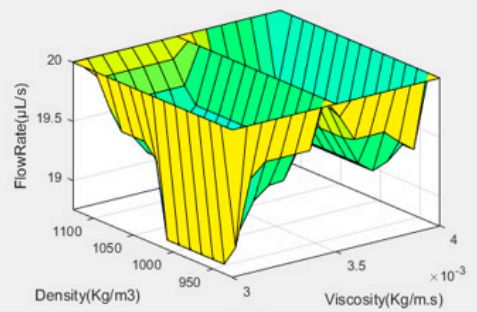

(c)

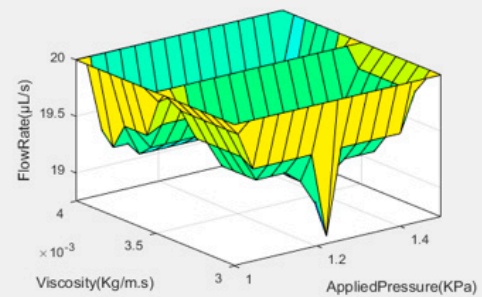

(e)

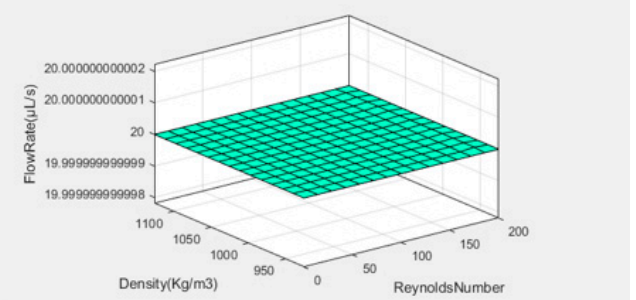

(b)

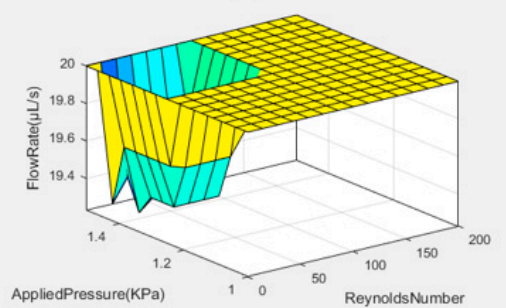

(d)

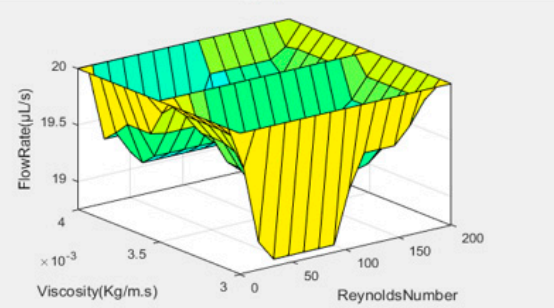

(f)

Figure 4. 3D graphical variations with inputs Reynolds number, applied pressure, viscosity, and density with flow rate as output. (a) Change for applied pressure with density and flow rate as output. (b) Variation for Reynolds number with density and flow rate as output. (c) Change for viscosity with density and flow rate as output. (d) Variation for applied pressure with Reynolds number and flow rate as output. (e) Difference for applied pressure with viscosity and flow rate as output. (f) Variation for Reynolds number with viscosity and flow rate as output. 
The three-dimensional graphs obtained for 5CACMC from Fuzzy logic simulation with velocity as output are shown below in Figure 5 .

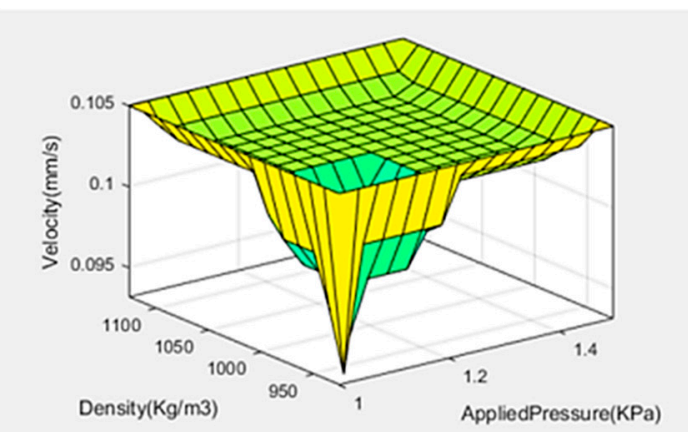

(a)

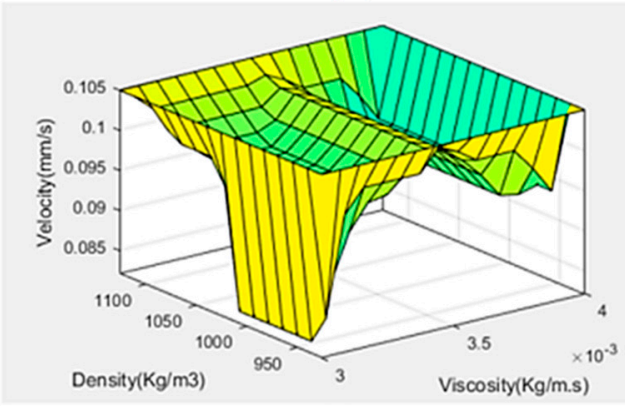

(c)

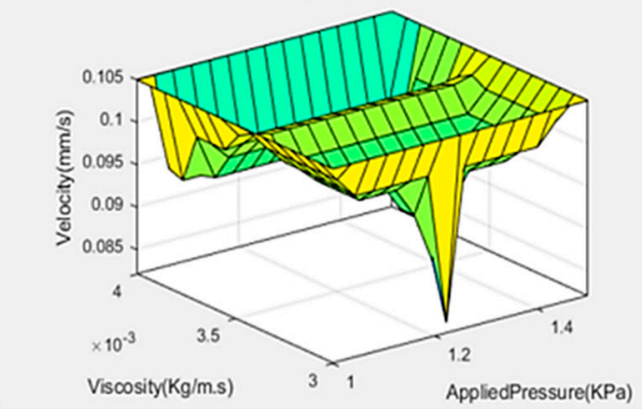

(e)

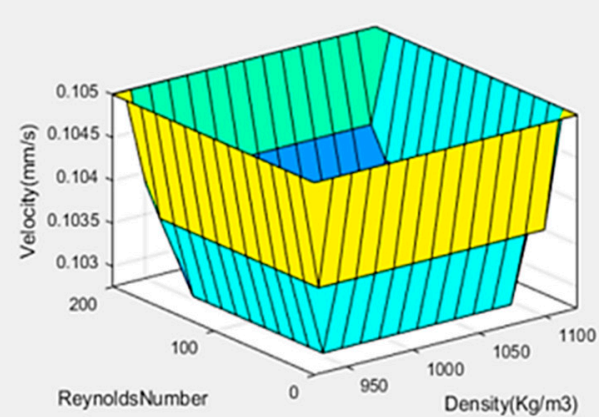

(b)

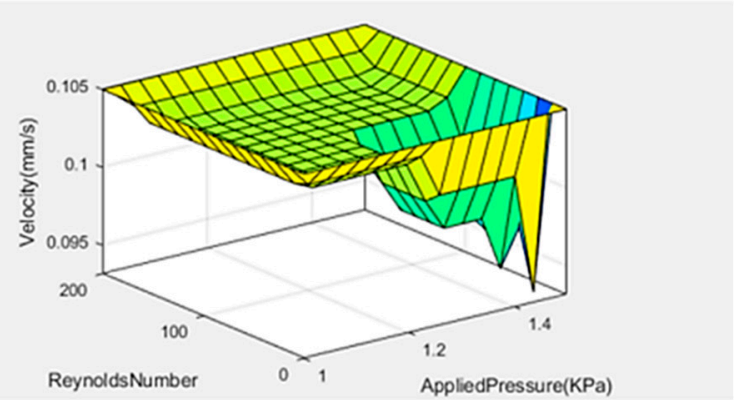

(d)

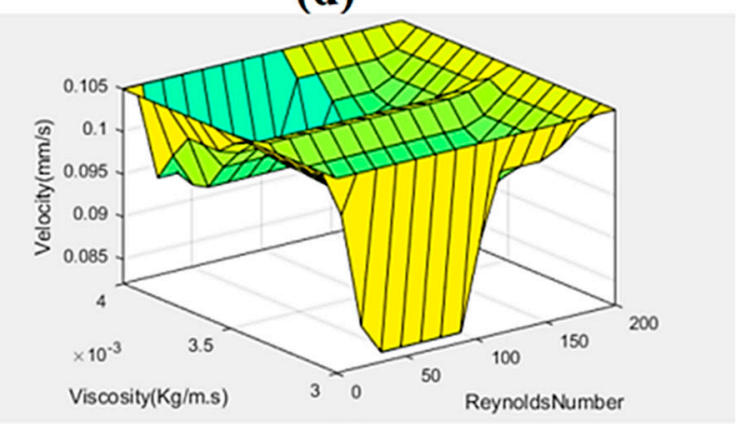

(f)

Figure 5. 3D graphical variations with inputs Reynolds number, applied pressure, viscosity, and density with velocity as output. (a) Variation for applied pressure with density and velocity as output. (b) Variation for Reynolds number with density and velocity as output. (c) Variation for viscosity with density and velocity as output. (d) Variation for applied pressure with Reynolds number and velocity as output. (e) Variation for applied pressure with viscosity and velocity as output. (f) Variation for Reynolds number with viscosity and velocity as output.

The three-dimensional graphs obtained for 5CACMC from Fuzzy logic simulation with pressure drop as output are shown below in Figure 6. 


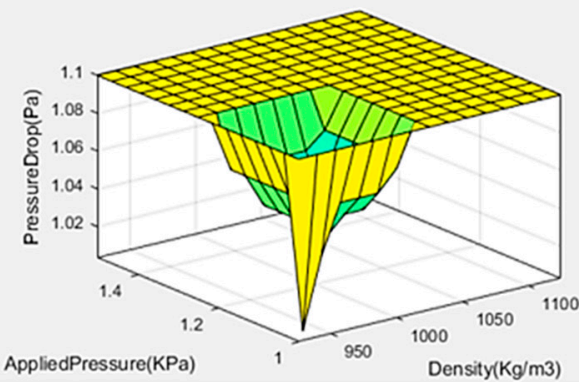

(a)

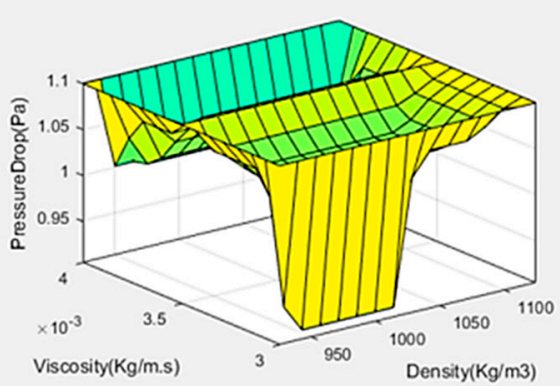

(c)

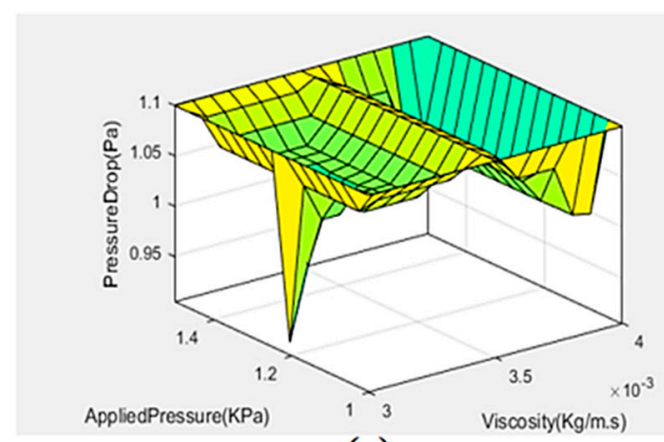

(e)

(e)

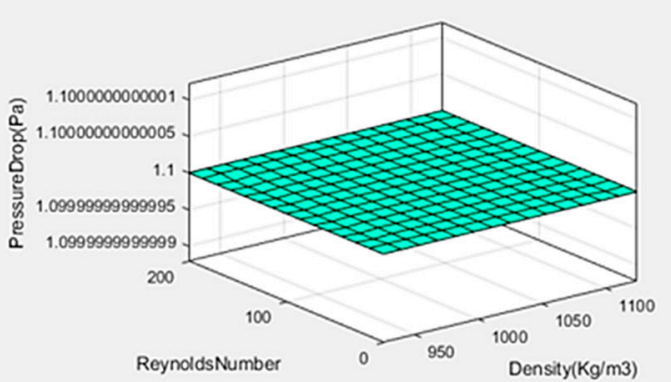

(b)

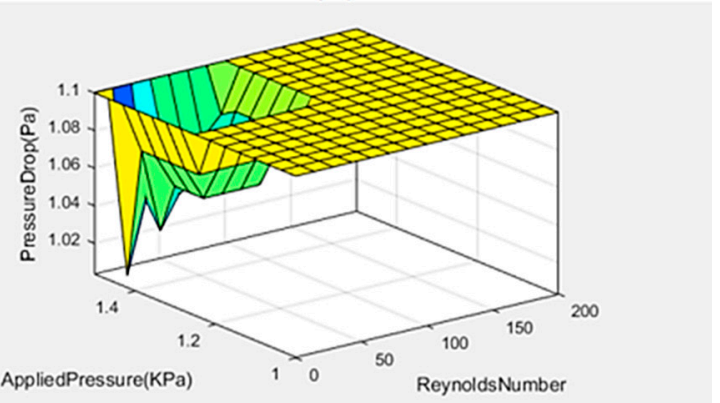

(d)

Figure 6. 3D graphical variations with inputs Reynolds number, applied pressure, viscosity, and density with flow rate as output (a) Variation for applied pressure with density and pressure drop as output (b) Variation for Reynolds number with density and pressure drop as output (c) Variation for viscosity with density and pressure drop as output (d) Variation for applied pressure with Reynolds number and pressure drop as output (e) Variation for applied pressure with viscosity and pressure drop as output (f) Variation for Reynolds number with viscosity and pressure drop as output.

The three-dimensional graphs obtained for 5CDCMC from Fuzzy logic simulation with flow rate as output are shown below in Figure 7. 


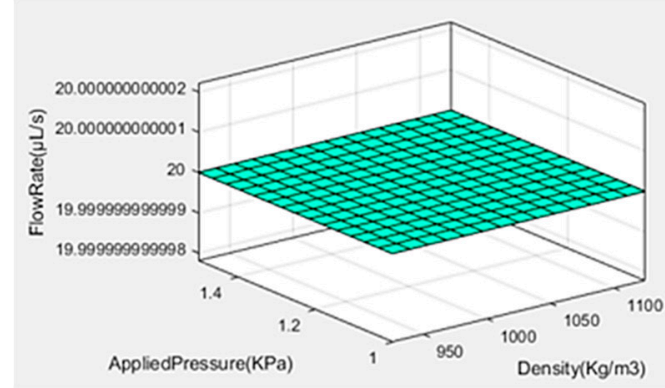

(a)

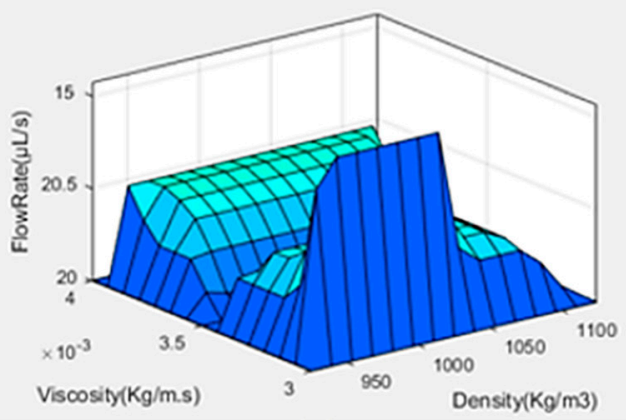

(c)

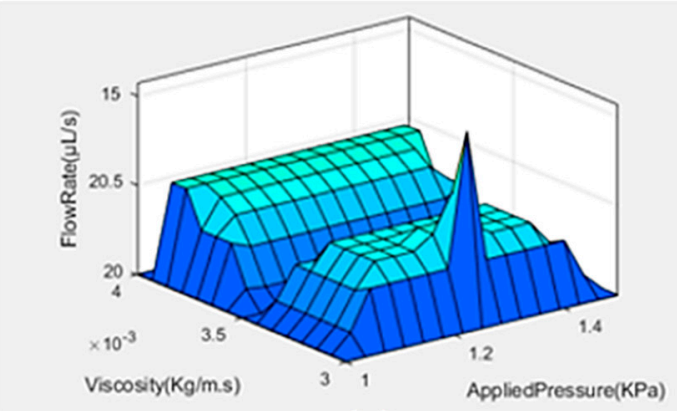

(e)

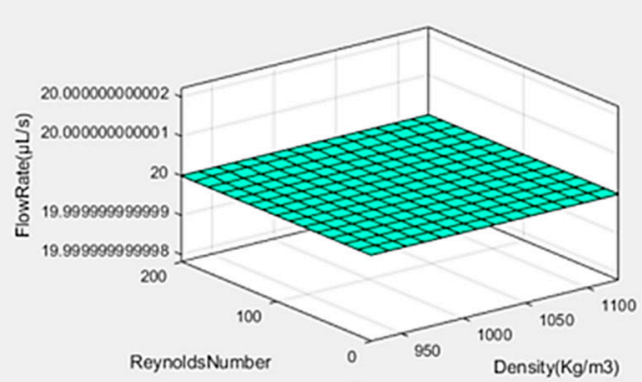

(b)

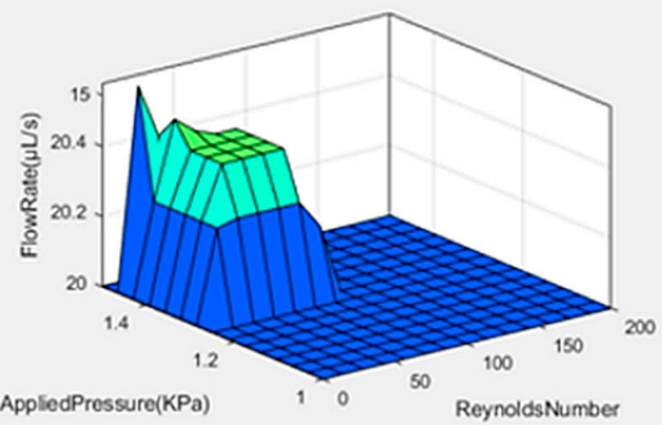

(d)

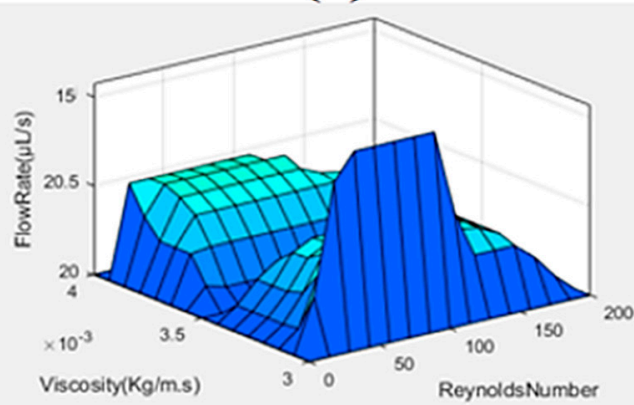

(f)

Figure 7. 3D graphical variations with inputs Reynolds number, applied pressure, viscosity, and density with flow rate as output (a) Variation for applied pressure with density and flow rate as output (b) Variation for Reynolds number with density and flow rate as output (c) Variation for viscosity with density and flow rate as output (d) Variation for applied pressure with Reynolds number and flow rate as output (e) Variation for applied pressure with viscosity and flow rate as output (f) Variation for Reynolds number with viscosity and flow rate as output.

The three-dimensional graphs obtained for 5CDCMC from Fuzzy logic simulation with velocity as output are shown below in Figure 8. 


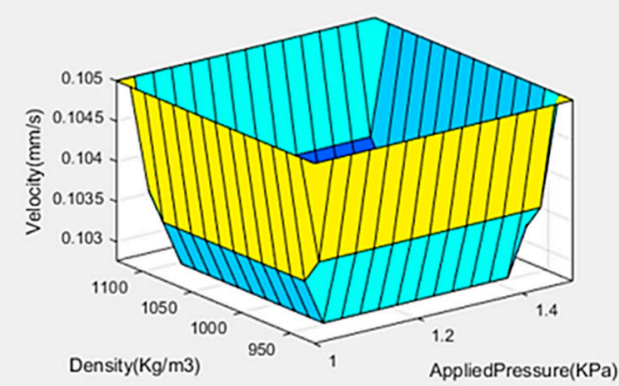

(a)

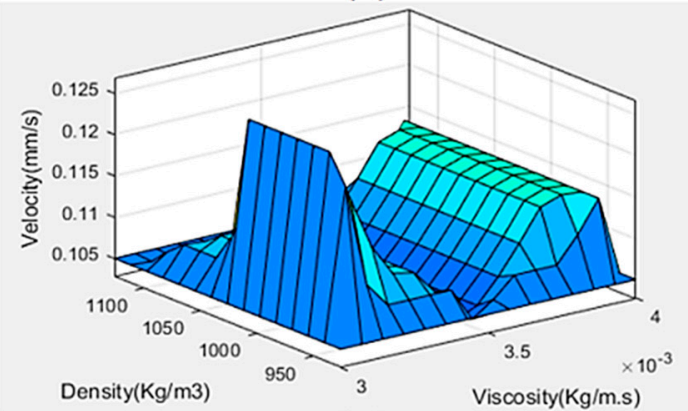

(c)

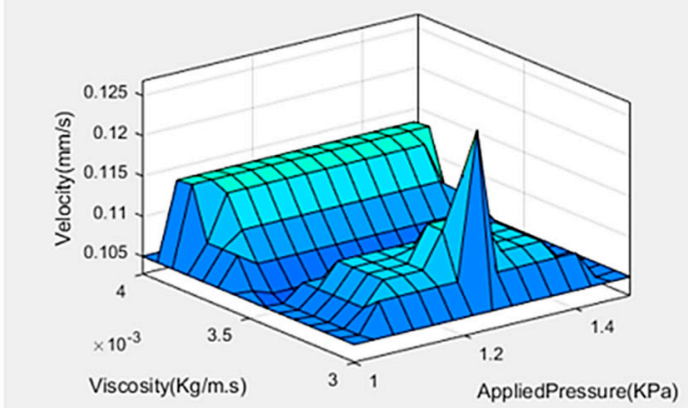

(e)

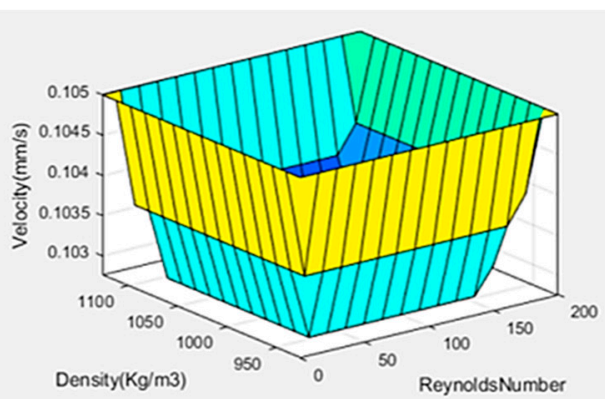

(b)

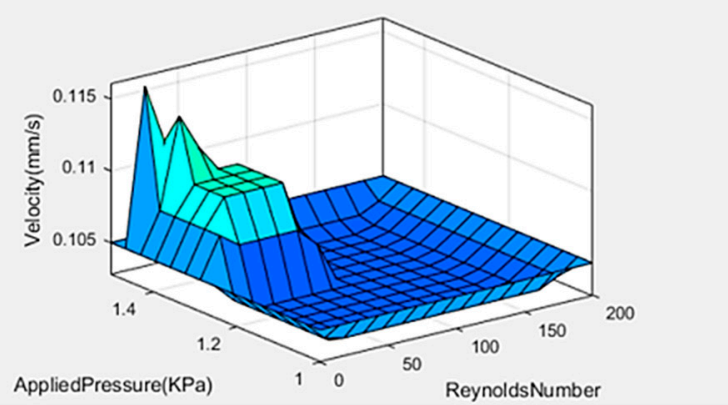

(d)

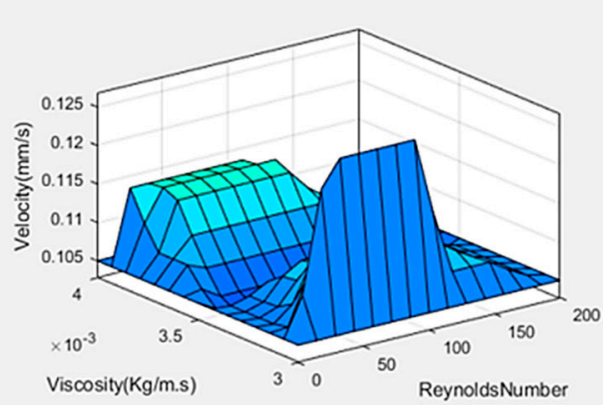

(f)

Figure 8. 3D graphical variations with inputs Reynolds number, applied pressure, viscosity, and density with flow rate as output (a) Variation for applied pressure with density and velocity as output (b) Variation for Reynolds number with density and velocity as output (c) Variation for viscosity with density and velocity as output (d) Variation for applied pressure with Reynolds number and velocity as output (e) Variation for applied pressure with viscosity and velocity as output (f) Variation for Reynolds number with viscosity and velocity as output.

The three-dimensional graphs obtained for 5CDCMC from Fuzzy logic simulation with pressure drop as output are shown below in Figure 9. 


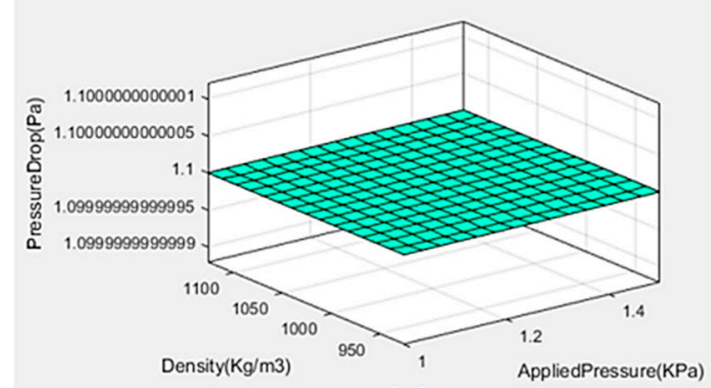

(a)

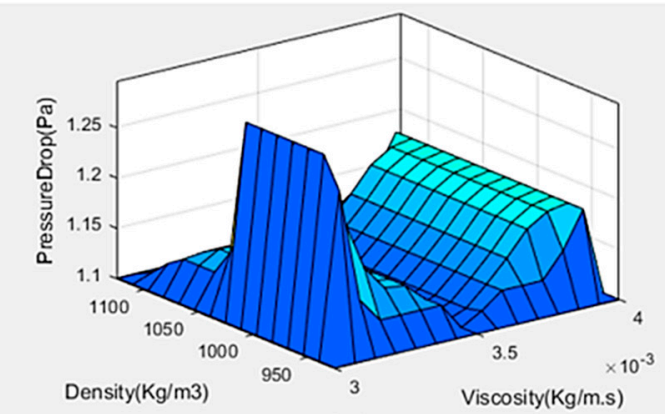

(c)

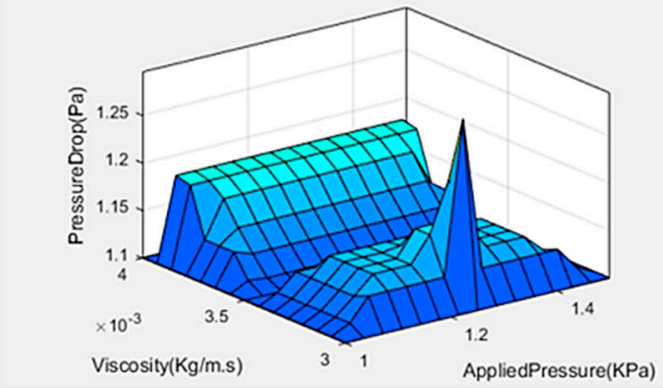

(e)

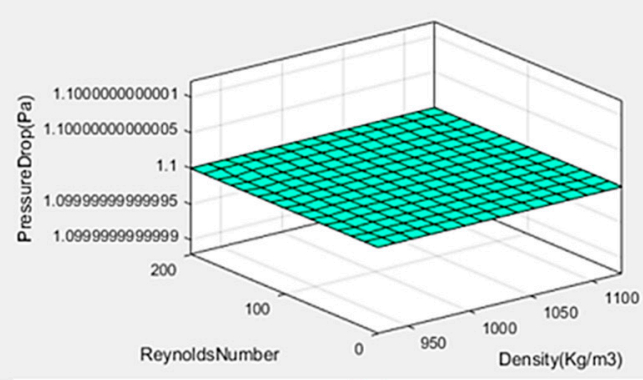

(b)

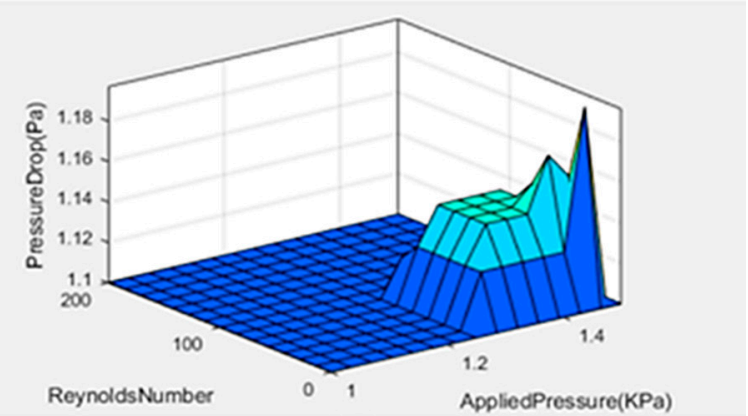

(d)

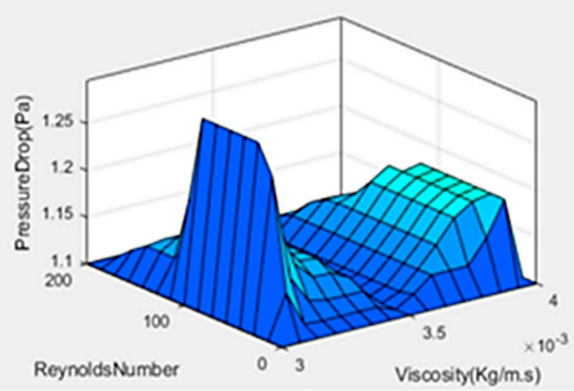

(f)

Figure 9. 3D graphical variations with inputs Reynolds Number, applied pressure, viscosity, and density with flow rate as output (a) Variation for applied pressure with density and pressure drop as output (b) Variation for Reynolds number with density and pressure drop as output (c) Variation for viscosity with density and pressure drop as output (d) Variation for applied pressure with Reynolds number and pressure drop as output (e) Variation for applied pressure with viscosity and pressure drop as output (f) Variation for Reynolds number with viscosity and pressure drop as output.

The results assessment for simulation and using Mamdani model is shown in Table 3.

Table 3. Results assessment for both types of microchannels (Mamdani's numerical value with Fuzzy simulation MATLAB).

\begin{tabular}{|c|c|c|c|c|c|c|c|c|}
\hline Microchannel & $\begin{array}{c}\text { Reynolds } \\
\text { Number }\end{array}$ & $\begin{array}{c}\text { Applied } \\
\text { Pressure } \\
\text { (Kpa) }\end{array}$ & $\begin{array}{l}\text { Viscosity } \\
\text { (Kg/ms) }\end{array}$ & $\begin{array}{c}\text { Density } \\
\left(\mathrm{kgm}^{-3}\right)\end{array}$ & Quantity & $\begin{array}{c}\text { Flow } \\
\text { Rate } \\
\left(\mu \mathrm{Ls}^{-1}\right)\end{array}$ & $\begin{array}{l}\text { Velocity } \\
(\mathrm{mm} / \mathrm{s})\end{array}$ & $\begin{array}{l}\text { Pressure } \\
\text { Drop(Pa) }\end{array}$ \\
\hline 5CACMC & 185 & 1.13 & 0.0032 & 1060 & $\begin{array}{c}\text { Mamdani's value } \\
\text { Fuzzy simulation } \\
\text { Dissimilarity } \\
\text { \%Error }\end{array}$ & $\begin{array}{c}19.72 \\
19.7 \\
0.02 \\
0.09 \%\end{array}$ & $\begin{array}{l}0.106 \\
0.105 \\
0.001 \\
0.9 \%\end{array}$ & $\begin{array}{c}1.19 \\
1.18 \\
0.01 \\
0.89 \%\end{array}$ \\
\hline 5CDCMC & 143 & 1.13 & 0.0032 & 1060 & $\begin{array}{c}\text { Mamdani's value } \\
\text { Fuzzy simulation } \\
\text { Dissimilarity } \\
\text { \%Error }\end{array}$ & $\begin{array}{c}15.41 \\
15.4 \\
0.01 \\
0.04 \%\end{array}$ & $\begin{array}{c}0.1042 \\
0.1032 \\
0.001 \\
0.9 \%\end{array}$ & $\begin{array}{c}1.16 \\
1.15 \\
0.01 \\
0.86 \%\end{array}$ \\
\hline
\end{tabular}


For 5CACMC, at Reynolds number 185, applied pressure $1.13 \mathrm{KPa}$, viscosity $0.0032 \mathrm{Kg} / \mathrm{ms}$, and blood density $1060 \mathrm{kgm}^{-3}$, the simulated values of $19.7 \mu \mathrm{Ls}^{-1}$ for flow rate, $0.105 \mathrm{~mm} / \mathrm{s}$ for velocity and $1.18 \mathrm{~Pa}$ drop in pressure have been observed. For 5CDCMC, at Reynolds number 143 , applied pressure $1.13 \mathrm{KPa}$, viscosity $0.0032 \mathrm{Kg} / \mathrm{m} . \mathrm{s}$ and blood density $1060 \mathrm{kgm}^{-3}$, the simulated value of $15.4 \mu \mathrm{Ls}^{-1}$ for flow rate, $0.1032 \mathrm{~mm} / \mathrm{s}$ for velocity and 1.15 Pa drop in pressure has been observed. Mamdani's numerical value was calculated for both channels by using mathematical relation [78]. The percentage errors in results are ignorable. The results are in agreement at Reynolds numbers 185 (for 5CACMC) and 143 (for 5CDCMC). Reynolds number 185 is higher than 143 because of more flow rate in 5CACMC. After fuzzy simulation, ANSYS Fluent simulation has been performed for the confirmation of obtained results.

\section{ANSYS Simulation of 5CACMC and 5CDCMC}

ANSYS has been extensively used in research, especially in the field of biomedical engineering $[42,43,79]$. With the help of the design modeler tool of ANSYS Fluent, the geometries of the channels (5CACMC and 5 CDCMC) have been created. After creating the geometries, mesh was performed with the mesh analysis successfully. In the setup tool, K-epsilon model was selected for the simulation because, in these channels, the flow is laminar with some turbulent shape at the curves of the channel. This model was also used because of the low Reynolds Numbers. There were four blood samples (young, old male and female with different blood densities, i.e., $950 \mathrm{Kg} / \mathrm{m}^{3}, 1000 \mathrm{Kg} / \mathrm{m}^{3}, 1060 \mathrm{Kg} / \mathrm{m}^{3}$ and $1125 \mathrm{Kg} / \mathrm{m}^{3}$. For simulation, the velocities were taken as 0.02 to $0.07 \mathrm{~m}$ per second and the pressure values were taken from 1 to 1.5 kilo Pascal [80]. Therefore, different velocities of the blood in veins were obtained in the result section of the ANSYS Fluent. The simulation results are shown below in Figure 10.

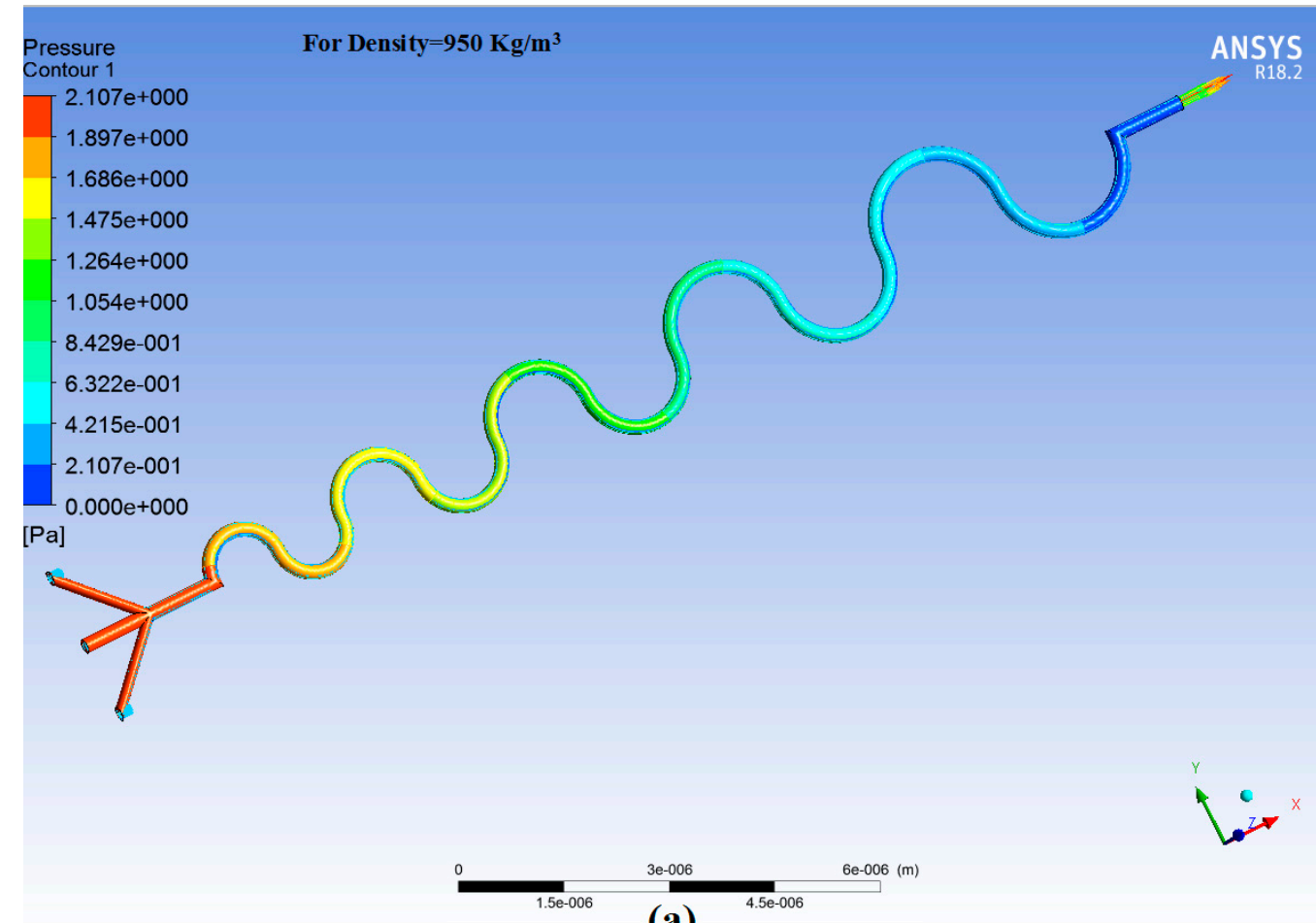

(a)

Figure 10. Cont. 


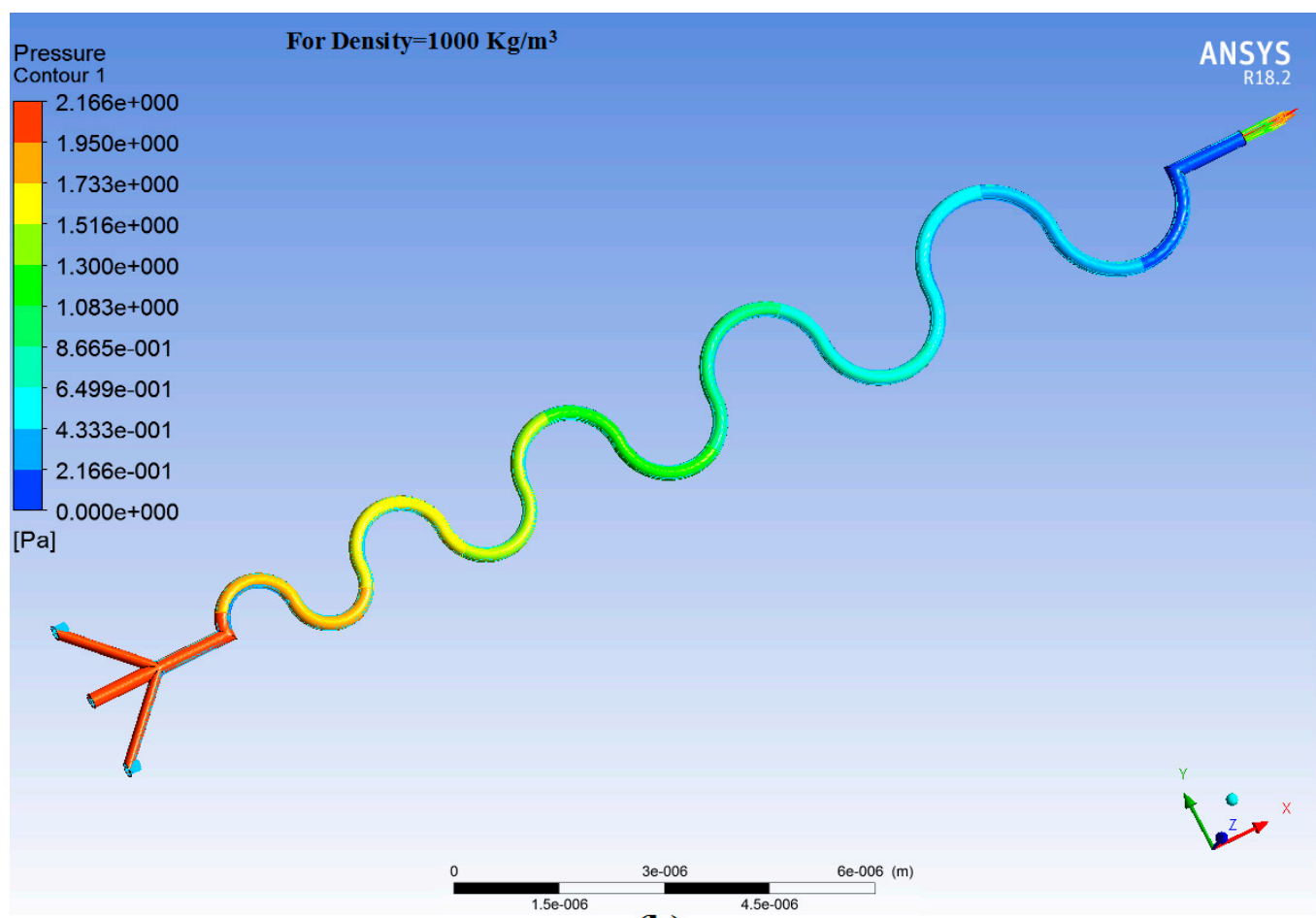

(b)

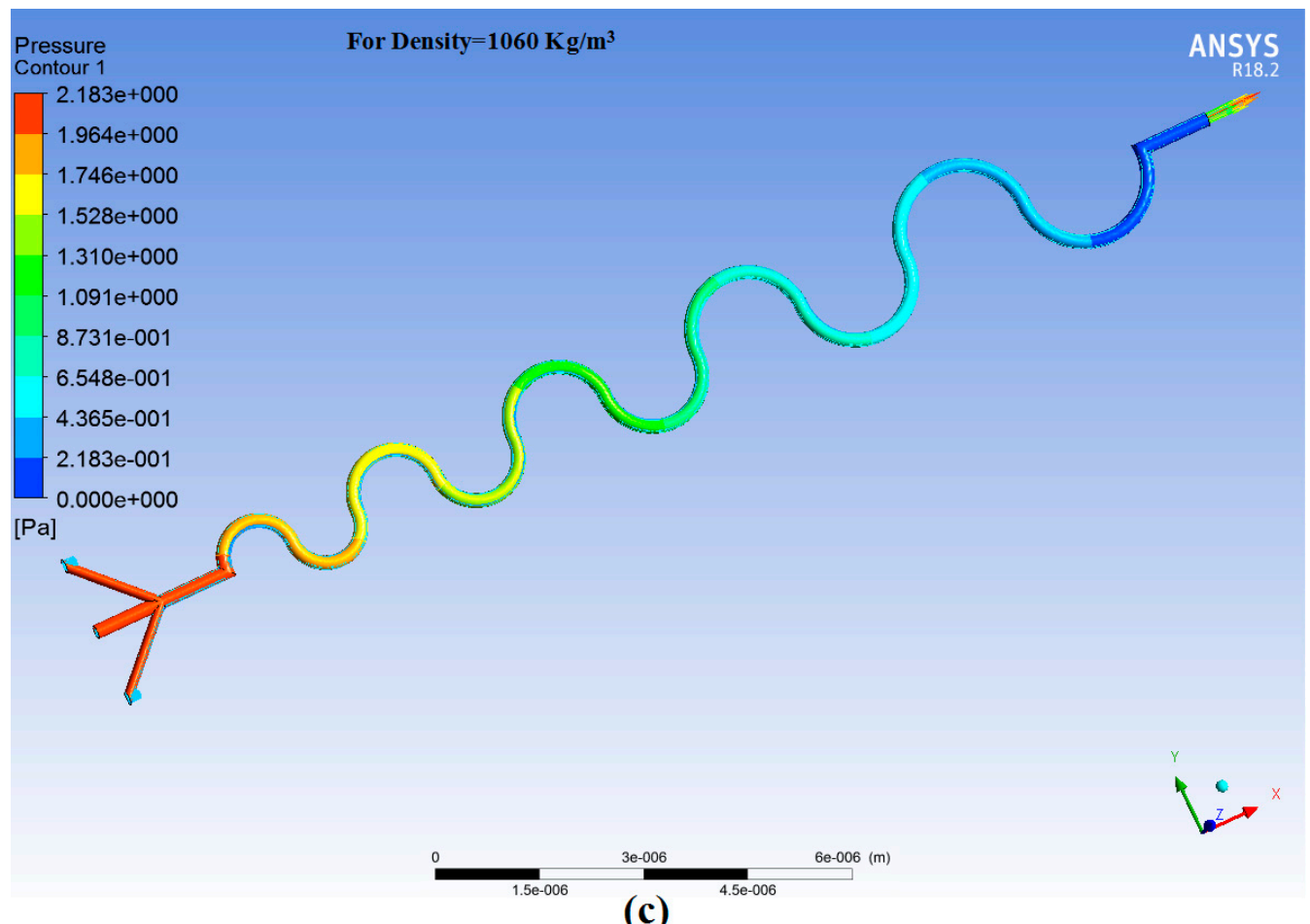

Figure 10. Cont. 

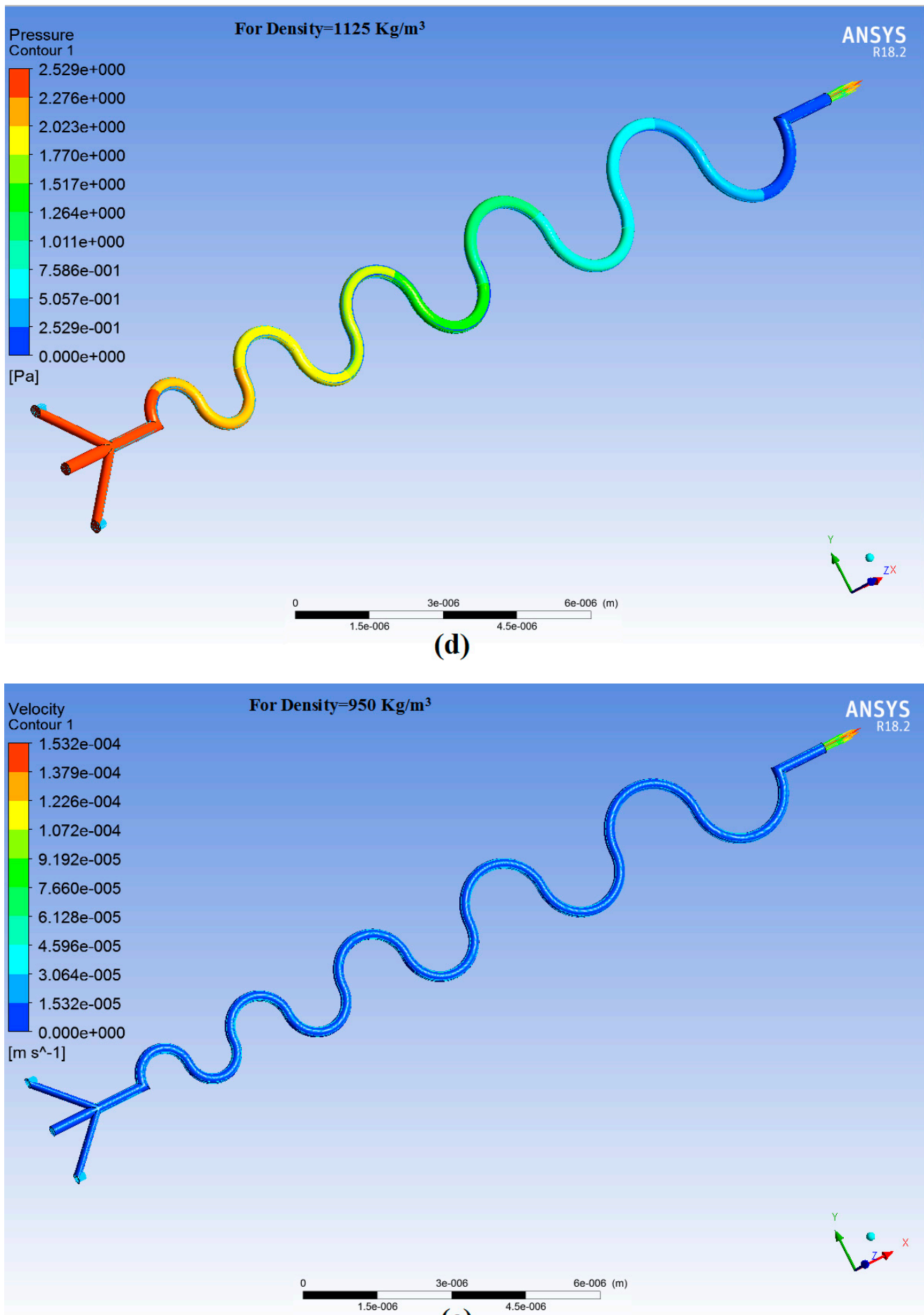

(e)

Figure 10. Cont. 

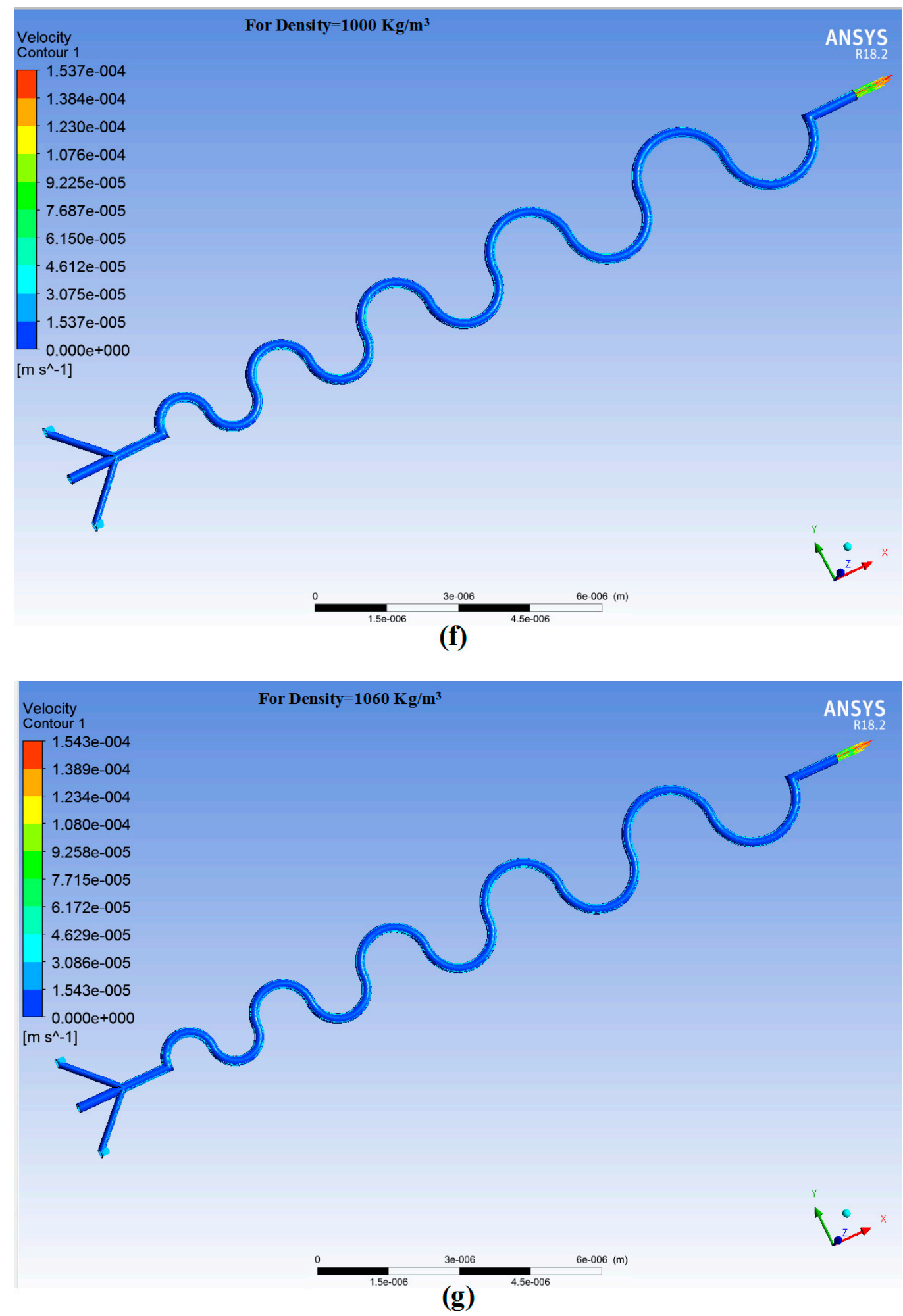

Figure 10. Cont. 


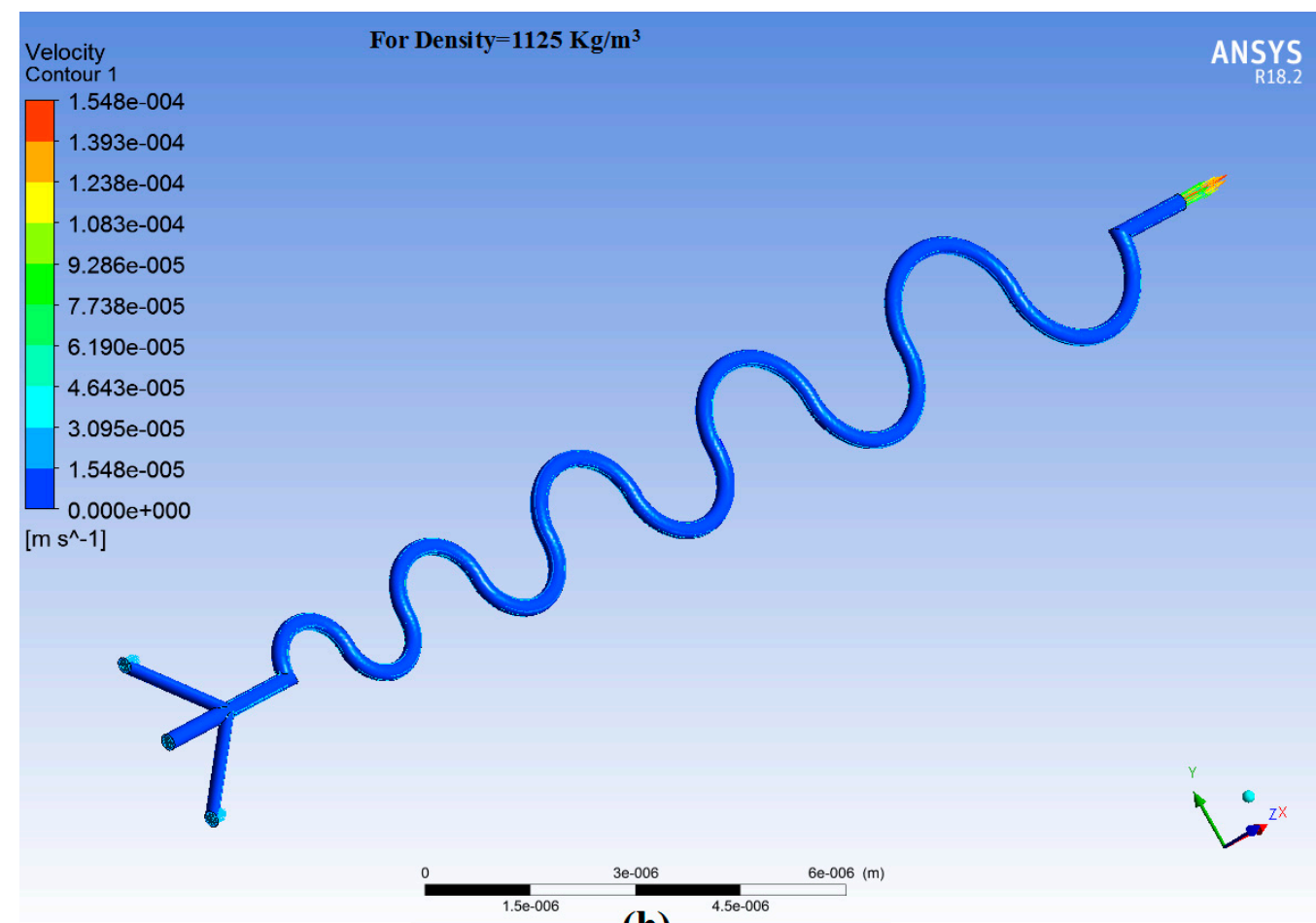

(h)

Figure 10. (a-h) Contours of Pressure and Velocity at different densities in the case of 5CACMC.

The simulation results for 5CDCMC are shown below in Figure 11.

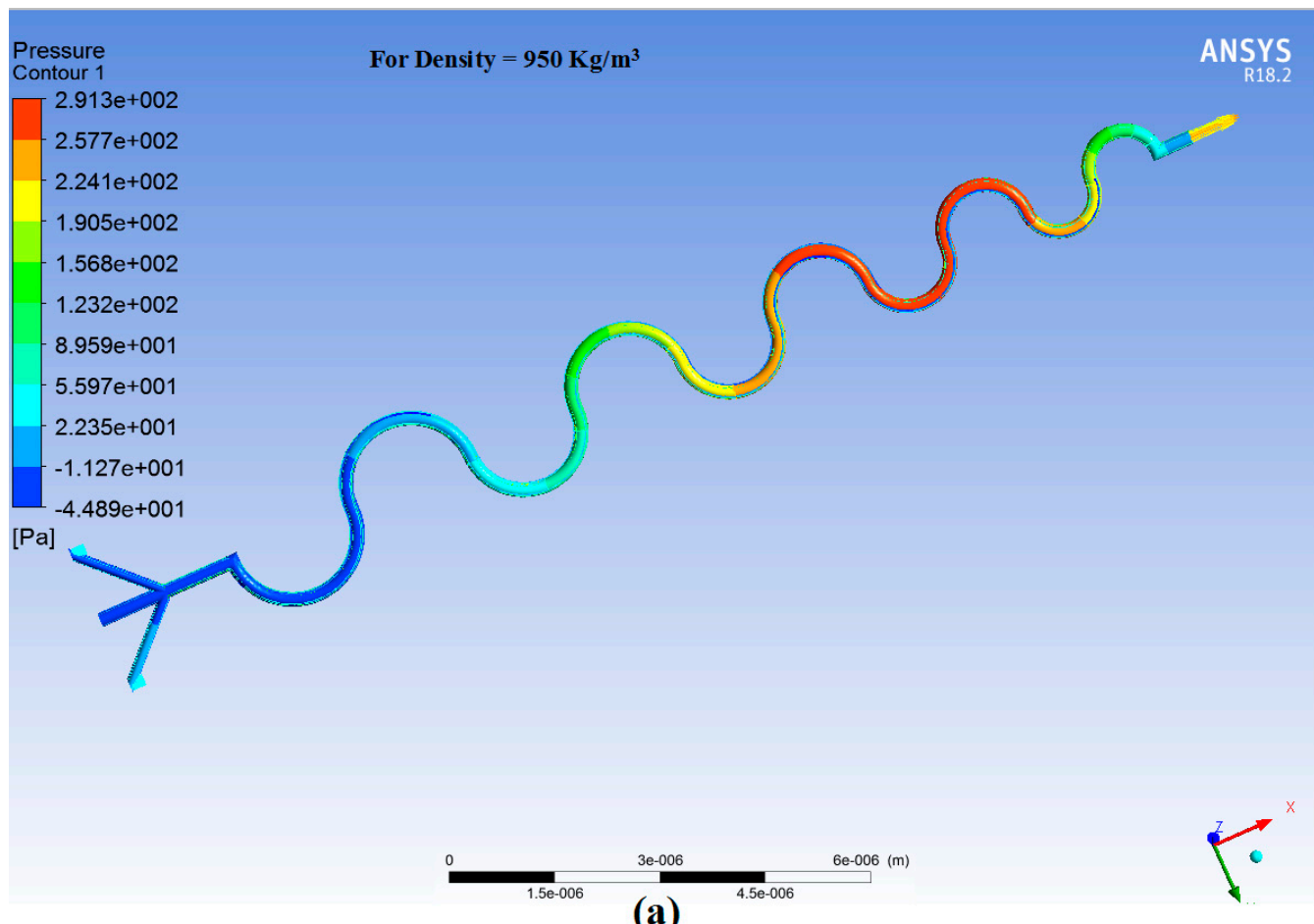

Figure 11. Cont. 


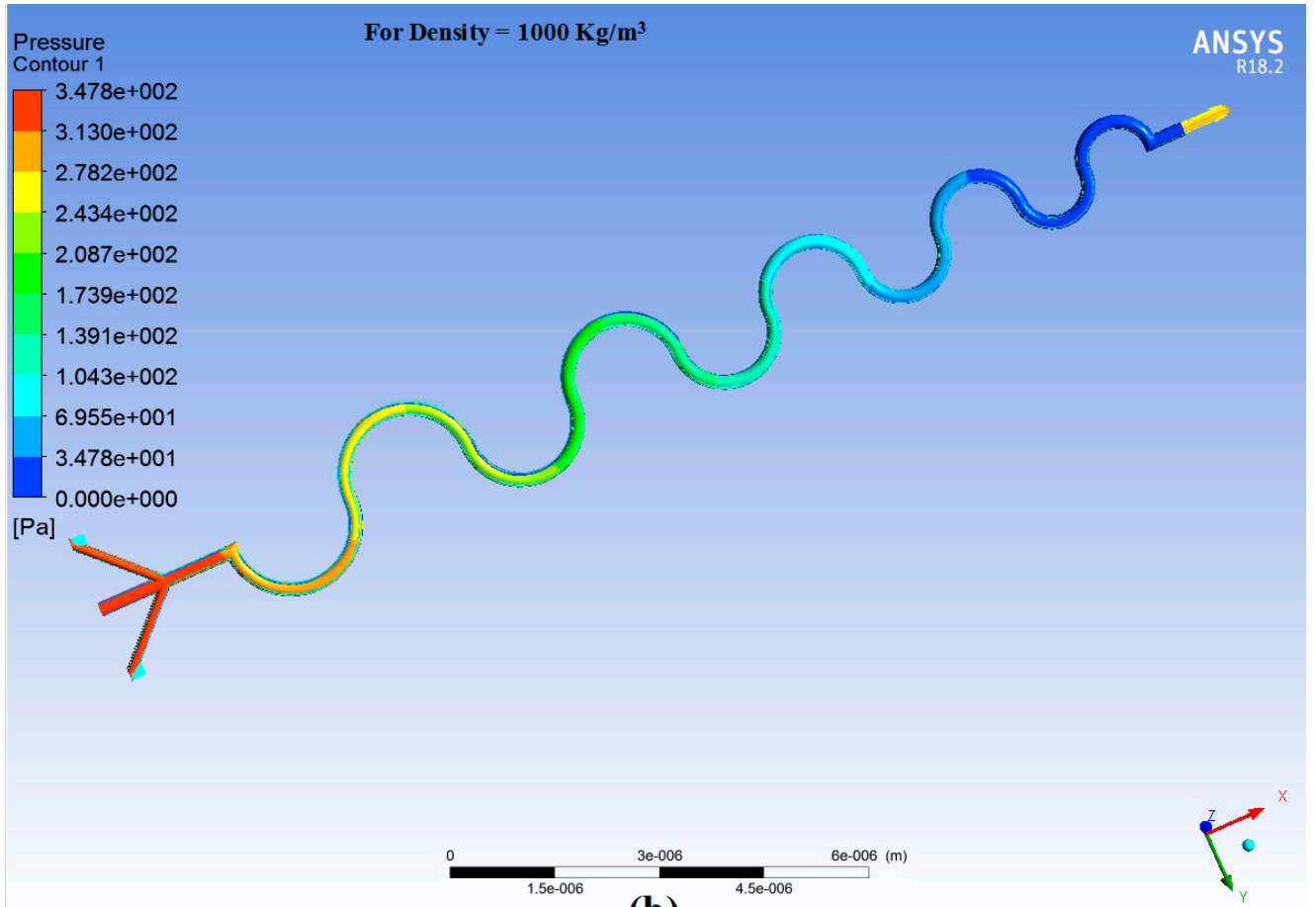

(b)

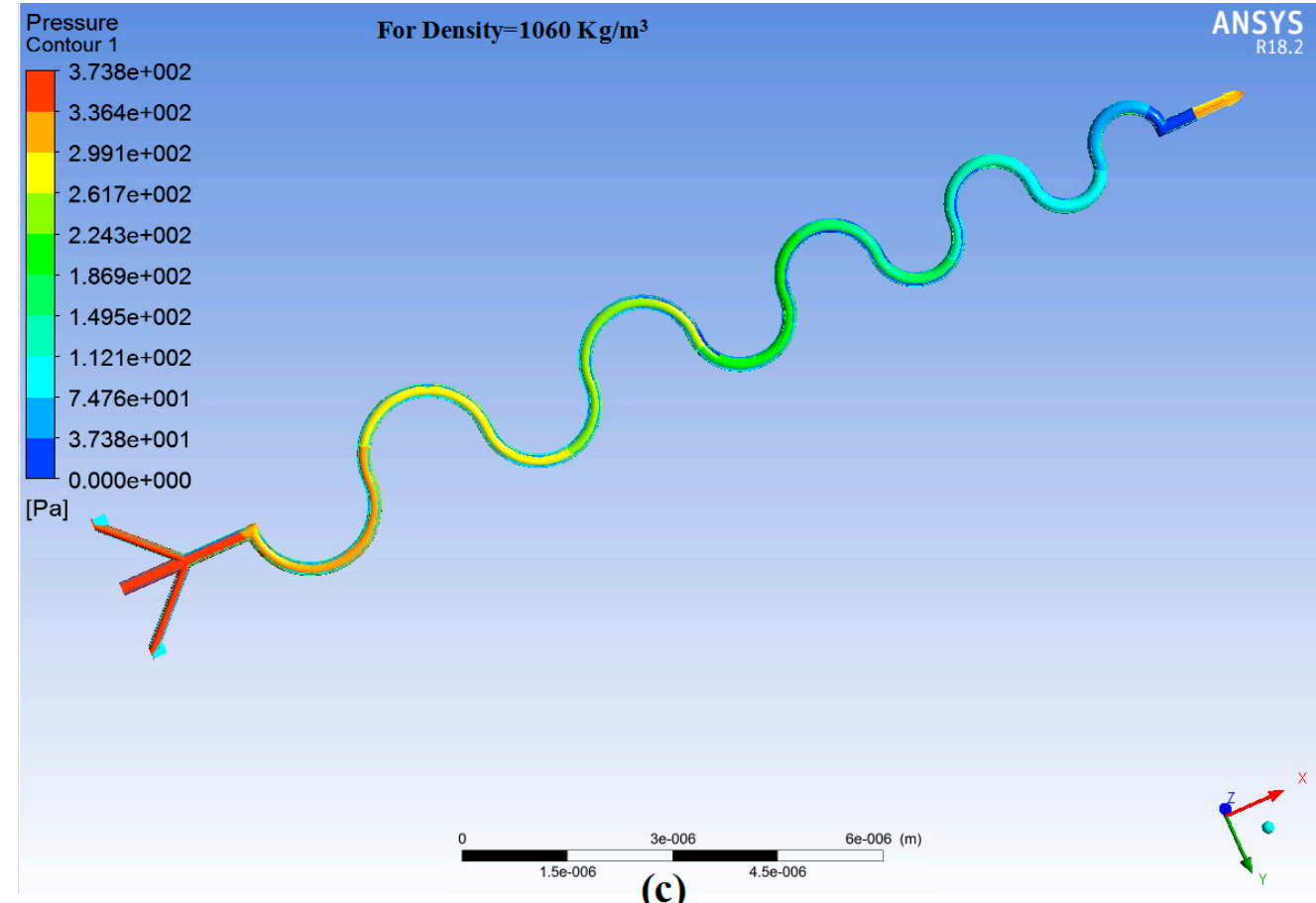

Figure 11. Cont. 


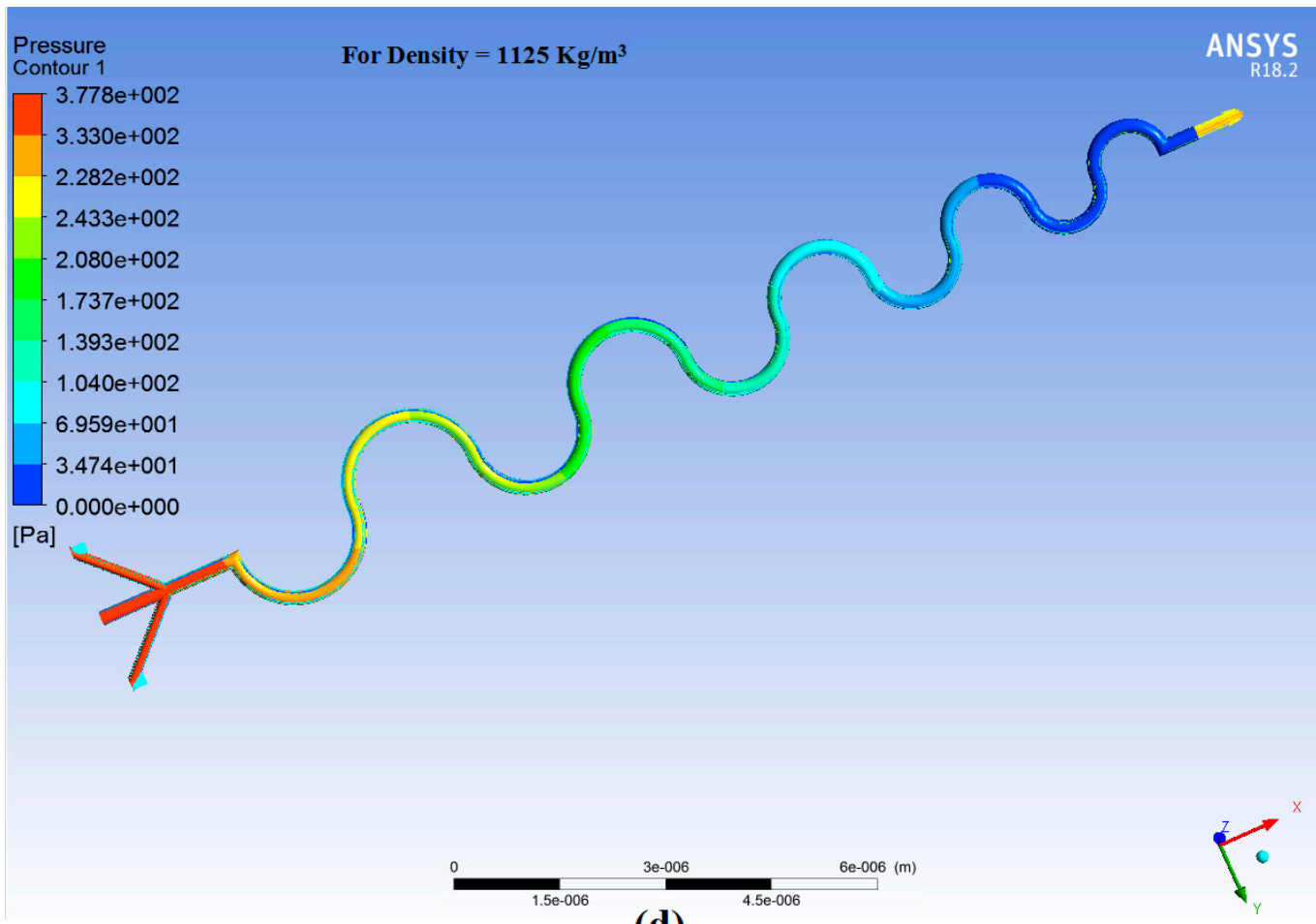

(d)

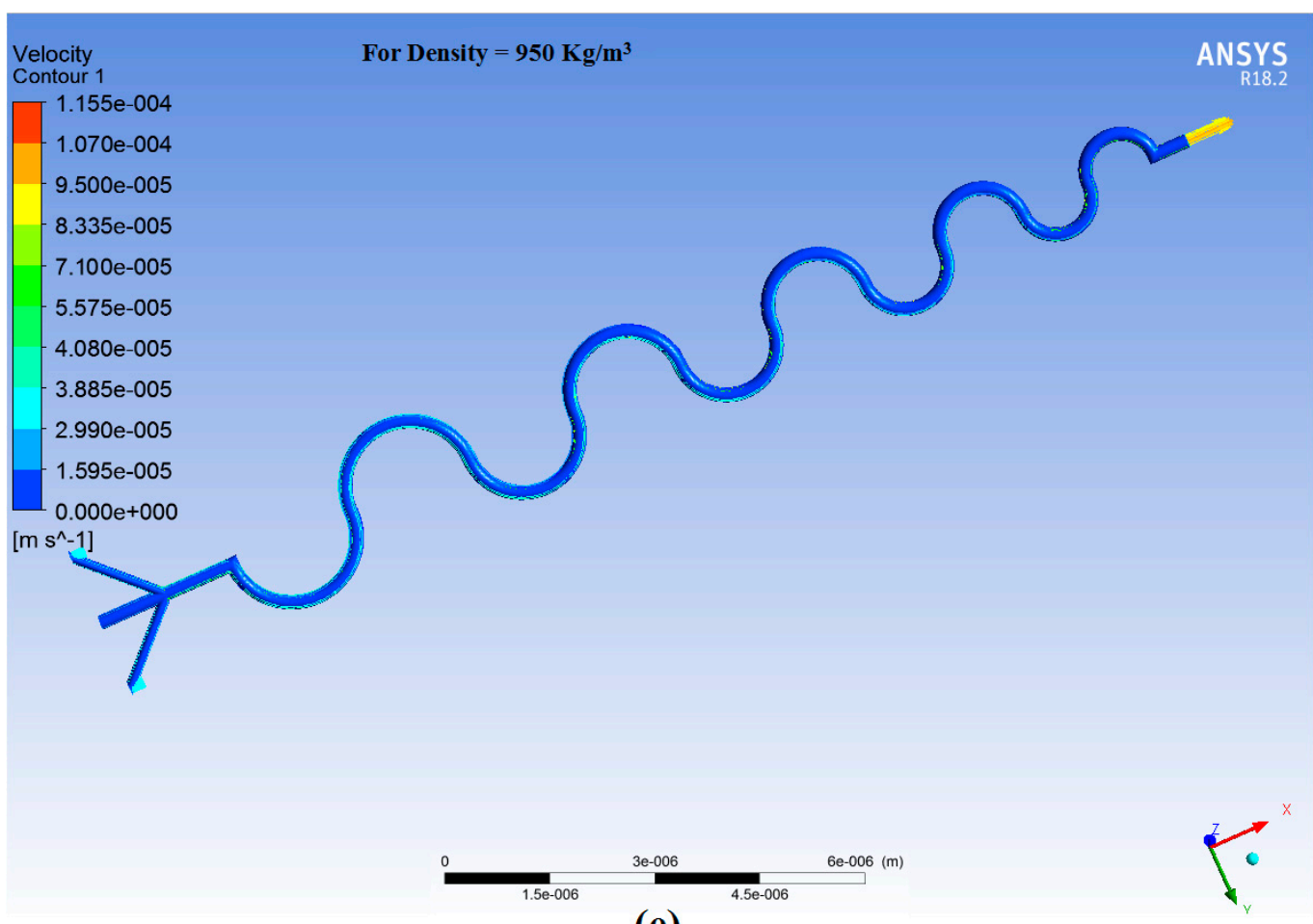

(e)

Figure 11. Cont. 

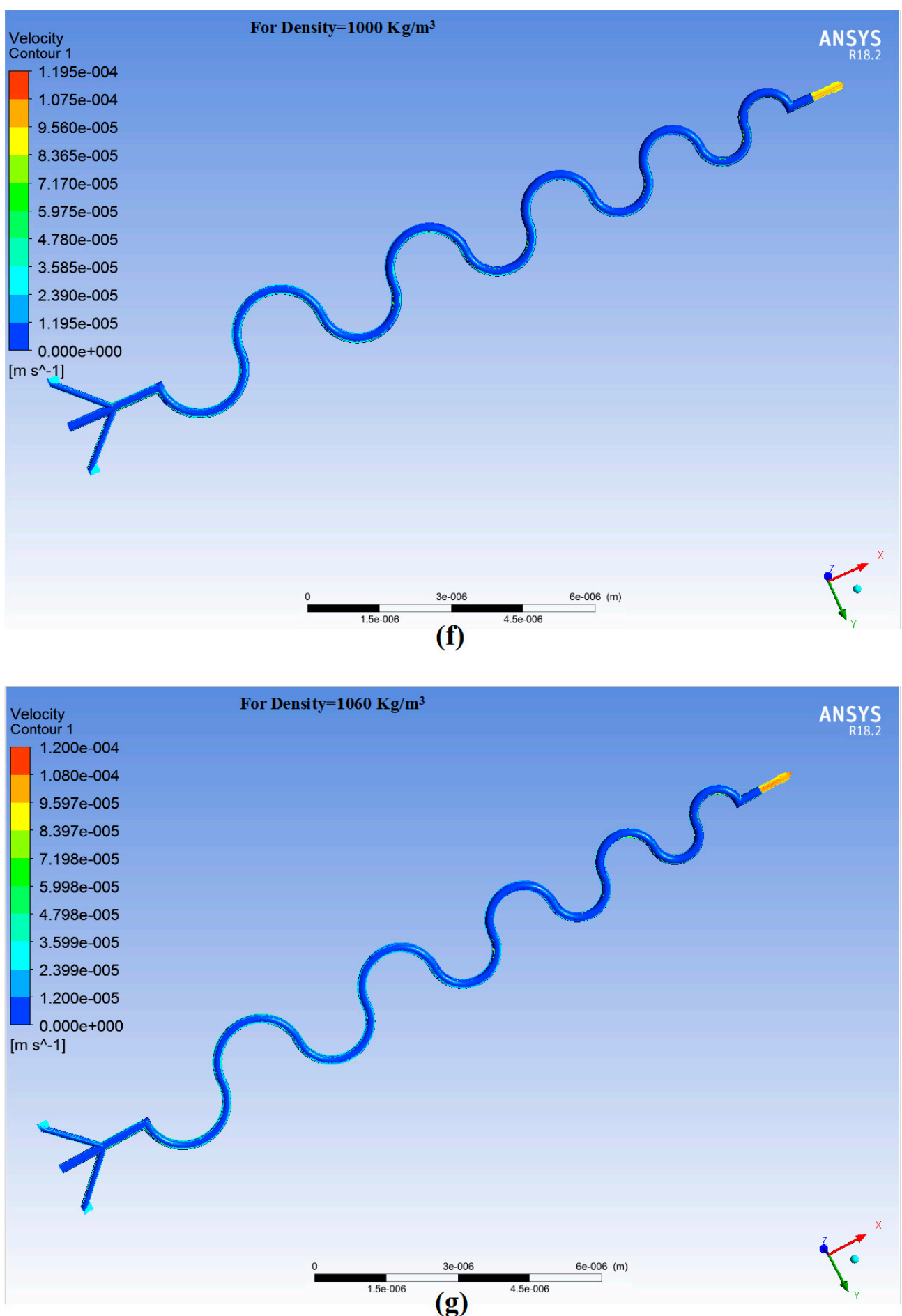

Figure 11. Cont. 


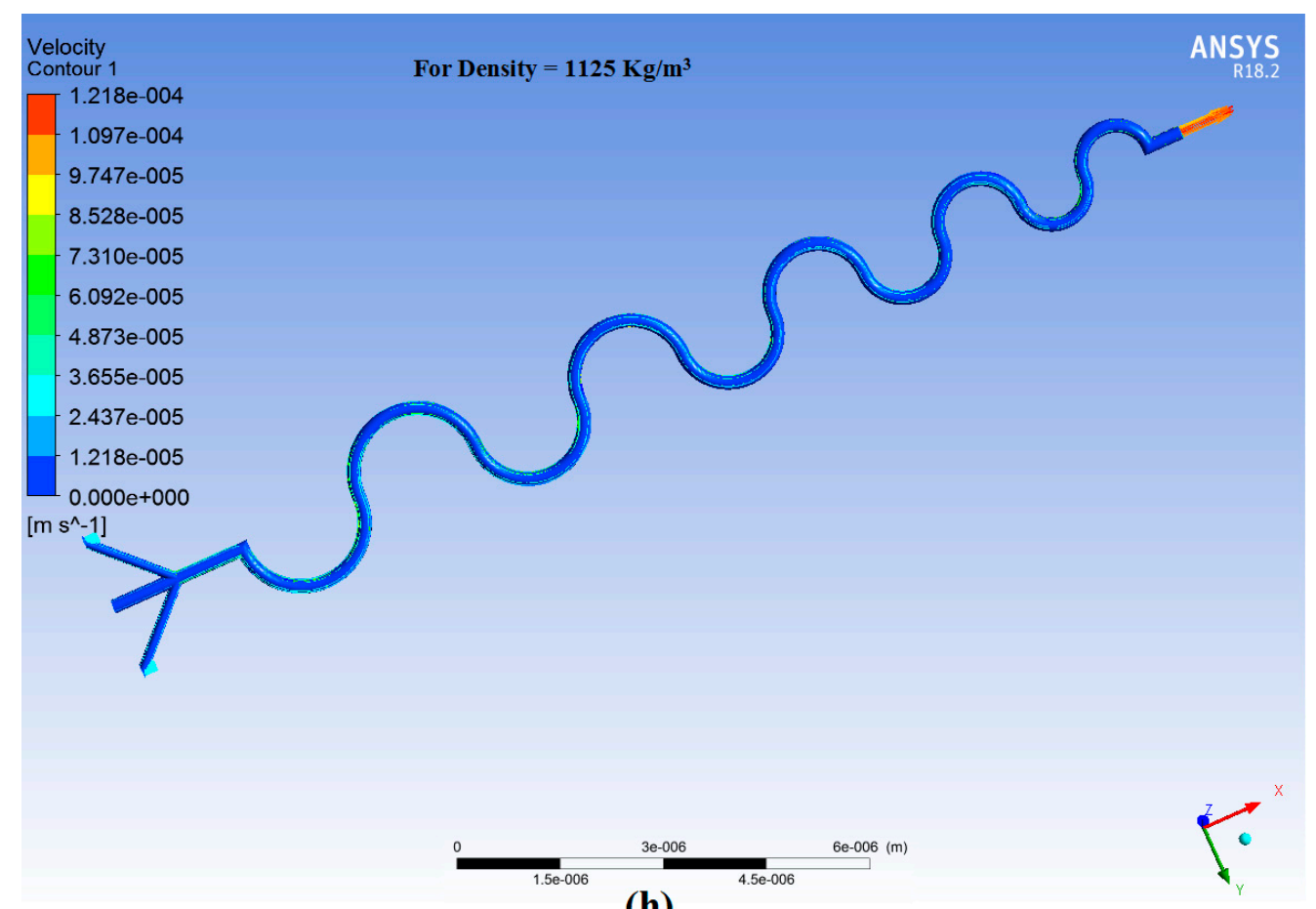

(h)

Figure 11. (a-h) Contours of Pressure and Velocity at different densities in the case of 5CDCMC.

The graphical results of ANSYS Fluent are described below. For 5CACMC, the graph between Reynolds number and pressure drop is shown in Figure 12a and the graph between the Reynolds number and the flow rate is shown in Figure 12b. These graphs have four different lines in different colors. The red, blue, yellow and green lines are shown with blood density 950, 1000, 1060, and $1125 \mathrm{kgm}^{-3}$, respectively. Data in Figure 12a shows that with the increase in Reynolds number, there is an increase in pressure drop. The maximum simulated pressure drop is $1.6 \mathrm{~Pa}$. The pressure drop was calculated by the following equation.

$$
\frac{\Delta p}{L}=\frac{128}{\pi} \frac{\mu Q}{D_{c}^{4}}
$$

Here, $\Delta p$ is the pressure drop, $\mu$ is the viscosity, $Q=\langle v\rangle \frac{\pi}{4} D_{c}^{2}$ is the flow rate, $D_{c}$ is the diameter of the channel. Reynolds numbers were calculated by the equation.

$$
R_{e}=\frac{\rho v D}{\mu}
$$

The graphical results are shown below for ANSYS simulation in Figure 12.

Figure $12 \mathrm{~b}$ shows that there is an increase in flow rate with the Reynolds number. At the first point, flow rate is increased up to $3.75 \%$, at the 2nd point, flow rate is increased up to $5.58 \%$, at the 3 rd point, flow rate is increased up to $7.38 \%$, at the 4 th point, flow rate is increased up to $9.23 \%$, at the 5th point, flow rate is increased up to $11.12 \%$, at the 6th point, flow rate is increased up to $12.83 \%$, at the 7 th point, flow rate is increased up to $14.83 \%$, at the 8 th point, flow rate is increased up to $16.59 \%$ and finally at the last point, flow rate is increased up to a maximum of $18.68 \%$. The flow rate has increased gradually. The maximum simulated flow rate is $19.3 \mu \mathrm{Ls}^{-1}$, with an average human blood density of $1060 \mathrm{kgm}^{-3}$.

For 5CDCMC, the graph between Reynolds number and pressure drop is shown in Figure 13a, and the graph between the Reynolds number and the flow rate is shown in Figure 13b. These graphs have four different lines in different colors. Data in Figure 13a shows that with the increase in Reynolds number, there is an increase in pressure drop. The maximum simulated pressure drop is $1.22 \mathrm{~Pa}$. 


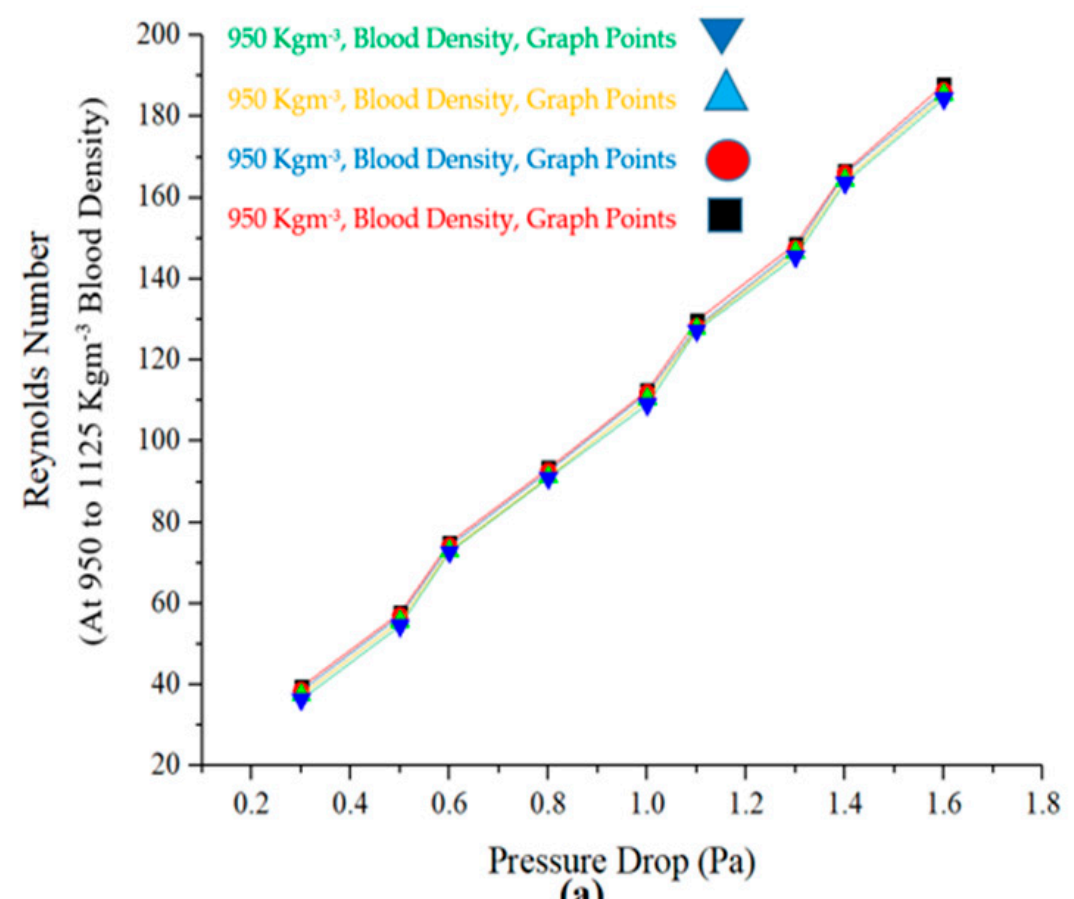

(a)

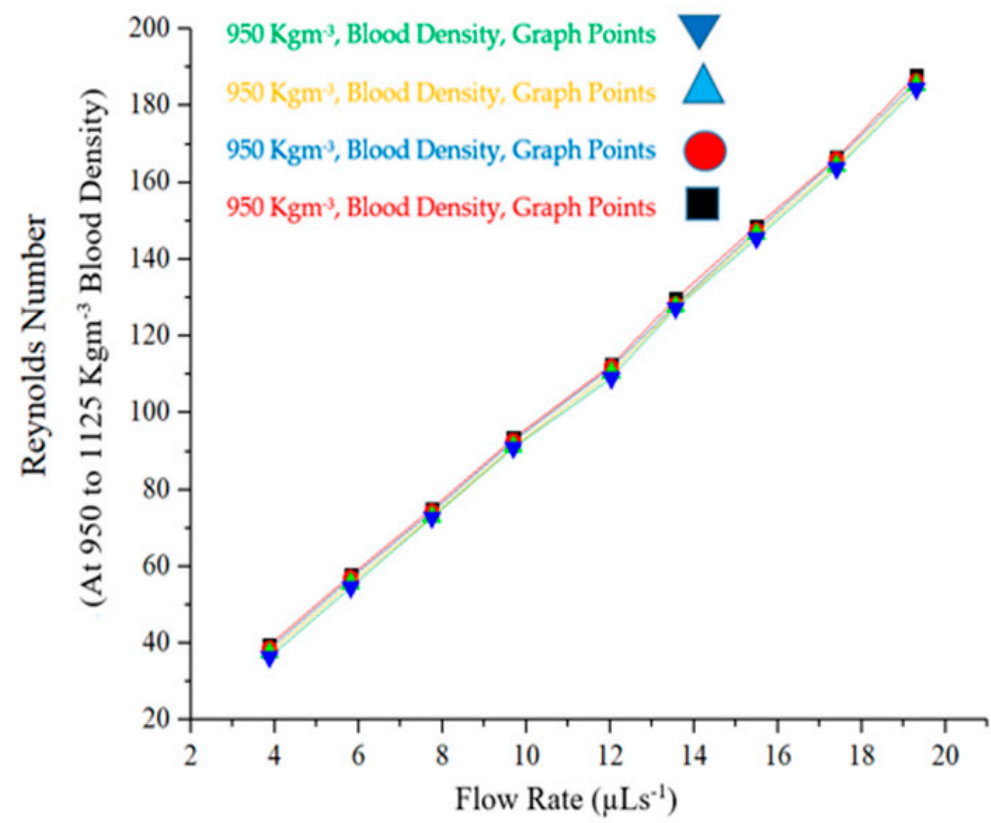

(b)

Figure 12. ANSYS Fluent Simulation graphs for 5CACMC (a) Reynolds number and pressure drop (b) Reynolds number and flow rate. 


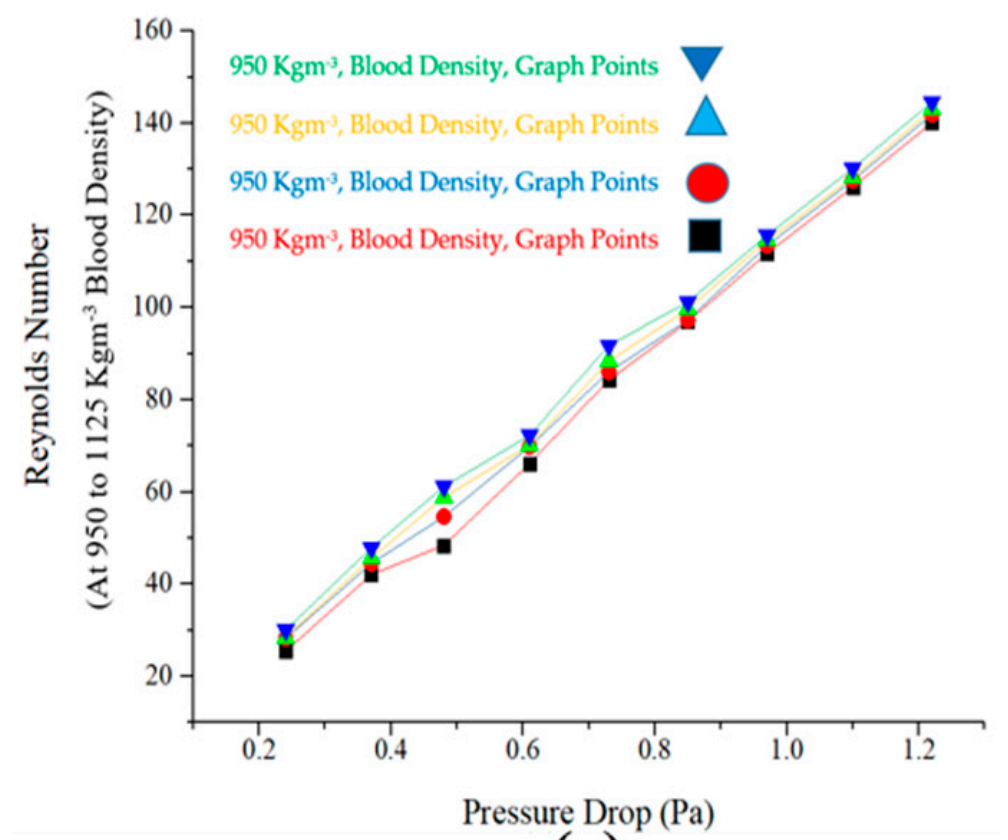

(a)

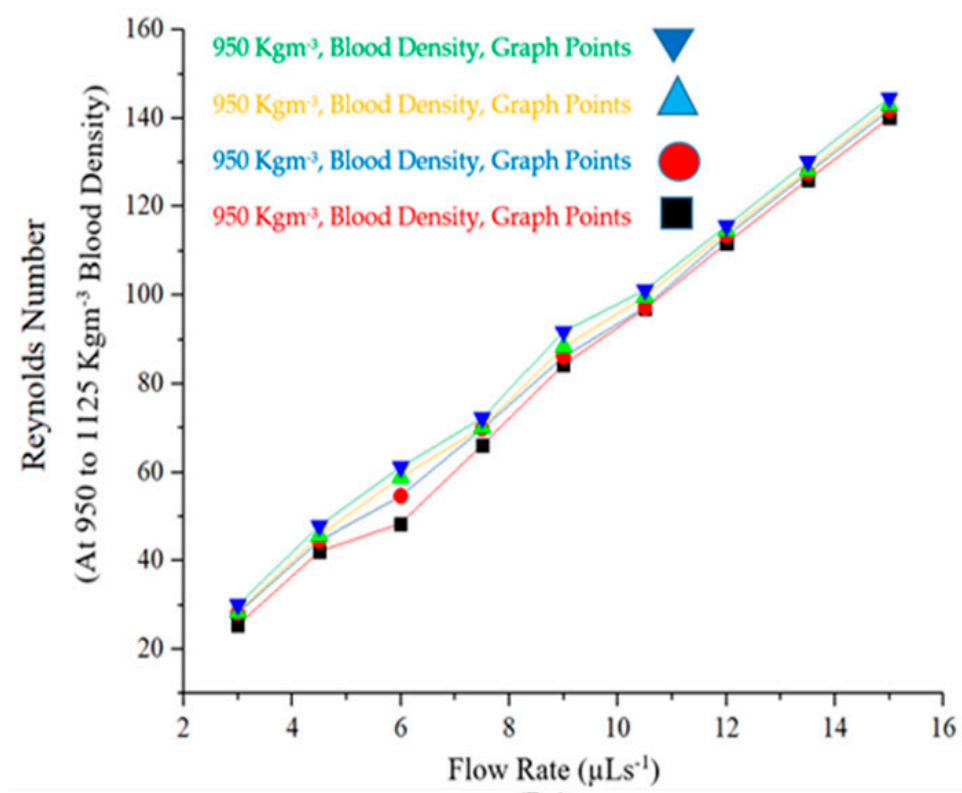

(b)

Figure 13. ANSYS Fluent Simulation graphs for 5CDCMC (a) Reynolds number and pressure drop (b) Reynolds number and flow rate.

Figure $13 \mathrm{~b}$ shows that there is an increase in flow rate with the Reynolds number. At the first point flow rate is increased up to $3.7 \%$, at the 2 nd point flow rate is increased up to $5.83 \%$, at the 3 rd point flow rate is increased up to $7.16 \%$, at the 4 th point flow rate is increased up to $9.15 \%$, at the 5 th point flow rate is increased up to $11.27 \%$, at the 6 th point flow rate is increased up to $12.74 \%$, at the 7 th point flow rate is increased up to $14.86 \%$, at the 8 th point flow rate is increased up to $16.7 \%$ and finally at the last point flow rate is increased up to a maximum of $18.58 \%$. The flow rate has increased gradually. The maximum simulated flow rate is $15 \mu \mathrm{Ls}^{-1}$, with an average human blood density of $1060 \mathrm{kgm}^{-3}$. 
The ANSYS simulation results (at the same input conditions that were used in Fuzzy MATLAB simulation) are shown in Table 4.

Table 4. ANSYS Results.

\begin{tabular}{|c|c|c|c|c|c|c|c|c|}
\hline Channel & $\begin{array}{c}\text { Applied } \\
\text { Pressure } \\
\text { (KPa) }\end{array}$ & $\begin{array}{c}\text { Blood } \\
\text { Viscosity } \\
(\mathrm{Kg} / \mathrm{ms})\end{array}$ & $\begin{array}{c}\text { Average Blood } \\
\text { Density } \\
\left(\mathrm{kgm}^{-3}\right)\end{array}$ & $\begin{array}{c}\text { Reynolds } \\
\text { Number }\end{array}$ & $\begin{array}{c}\text { Flow } \\
\text { Rate } \\
\left(\mu \mathrm{Ls}^{-1}\right)\end{array}$ & $\begin{array}{l}\text { Max. Channel } \\
\text { Pressure (Pa) }\end{array}$ & $\begin{array}{l}\text { Velocity } \\
(\mathrm{mm} / \mathrm{s})\end{array}$ & $\begin{array}{l}\text { Pressure } \\
\text { Drop (Pa) }\end{array}$ \\
\hline 5CACMC & \multirow{2}{*}{1.13} & \multirow{2}{*}{0.0032} & \multirow{2}{*}{1060} & 185 & 19.3 & 2.183 & 0.1543 & 1.6 \\
\hline 5CDCMC & & & & 143 & 15.0 & $3.738 \times 10^{2}$ & 0.120 & 1.22 \\
\hline
\end{tabular}

After these simulations, the authors have fabricated and tested the channels experimentally to optimize the final results.

\section{Fabrication}

The production of the five curved ascending and descending curvilinear micro-channel is completed with the method of photolithography. IoT devices were used to control the environment. PDMS has been sued for microchannels fabrication. The benefits of PDMS are replica molding, flexible, instinctively durable, exceptional properties of the polymer, translucent, suitable for microscopy, and high gas permeable. Firstly, the mask was designed on by using software and then these patterns were transfer on mask using silicon wafer with area $6 \times 6 \mathrm{~mm}^{2}$. Then silicone mold were fabricated. A Silicon wafer was washed through the solution of piranha $(\mathrm{H} 2 \mathrm{SO} 4+\mathrm{H} 2 \mathrm{O} 2)$. The coating was done with $\mathrm{SiO}_{2}$. It was baked nearly $210^{\circ} \mathrm{C}$ for approximately $1 \mathrm{~min}$ and $40 \mathrm{~s}$ for the dehydration of wafer. In the method of photolithography, the coating was done with photoresist PFI27C9 on the silicon wafer, which is spin-coated in the range of 800 to $3500 \mathrm{rpm}$ by using IoT controlled environment. Then the second phase was initiated, namely the exposure of PFI27C9 to ultraviolet light for a half minute. The mask was placed on a glass slide and finally accurately associated with PFI27C9 for the chemical reaction. Now the substrate was again baked at $100{ }^{\circ} \mathrm{C}$ for one minute. It was cooled then at room temperature. After the exposure, the required pattern of the channel of the mask on the substrate was obtained. Etching of silicon dioxide was completed by using deep reactive ion etching (DRIE) procedure in half an hour with oxide etcher machine. Etching of substrate was completed in $60 \mathrm{~min}$. After etching, the silicon mold was kept inside the stripping device for $60 \mathrm{~min}$. After all these phases, the PDMS elastomer was arranged. This mixture is then decanted with a prepared mold. For more toughening of PDMS, the substrate is baked at $75^{\circ} \mathrm{C}$ for up to $60 \mathrm{~min}$. Sterilization of PDMS material is an important step after fabrication process. It was sterilized by autoclaving. Fabricated material was exposed to high pressure $(110 \mathrm{kPa})$ steam at $120^{\circ} \mathrm{C}$ for $15 \mathrm{~min}$. All microorganisms were eliminated by this procedure. Lastly, the toughened PDMS is removed from the silicon wafer, and inputs and outputs are pierced. The glass slides and the PDMS are bonded with each other by baking in the oven for an hour. After final and complete fabrication, microchannels are shown in Figure 9. The total length of each channel is $1.6 \mathrm{~cm}$. The diameter of both channels is $400 \mu \mathrm{m}$. In the ascending channel, the first curve cycle has the radius $2.5 \mathrm{~mm}$, the 2nd cycle has $5 \mathrm{~mm}$, the 3 rd cycle has $7.5 \mathrm{~mm}$, the 4 th cycle has $10 \mathrm{~mm}$, and the 5 th cycle has $12.5 \mathrm{~mm}$. It has three inputs and one output. In the descending channel, the first curve cycle has the radius $12.5 \mathrm{~mm}$, the 2nd cycle has $10 \mathrm{~mm}$, the 3 rd cycle has $7.5 \mathrm{~mm}$, the 4 th cycle has $5 \mathrm{~mm}$, and the 5th cycle has $2.5 \mathrm{~mm}$. Both channels have three inputs and one output as shown in Figure 14. 


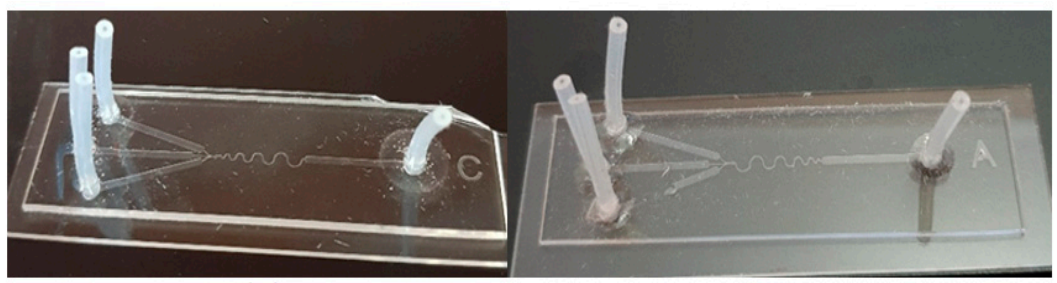

(a)

(b)

Figure 14. PDMS Microchannels (a) 5CACMC (b) 5CDCMC.

\section{Experimental Verification of Simulation Results}

To verify the simulated findings the experimentation for both channels was performed. For the experiment, three commercial mp6 micro-pumps with electronic circuits (mp6-EVA) were used. Heparin was mixed in the blood to avoid the clotting. With the help of a USB port, signals were given to all of the pumps. In the IoT controlled environment, three mp6 pumps were used for 5CACMC, because it has three inputs and one output. For $5 \mathrm{CDCMC}$, only one pump was utilized, because it has only one input and three outputs. Three pumps generated sufficient pressure for the continuous blood flow through both channels of diameter $400 \mu \mathrm{m}$. The actual experimental setup is shown in Figure 15a,b.

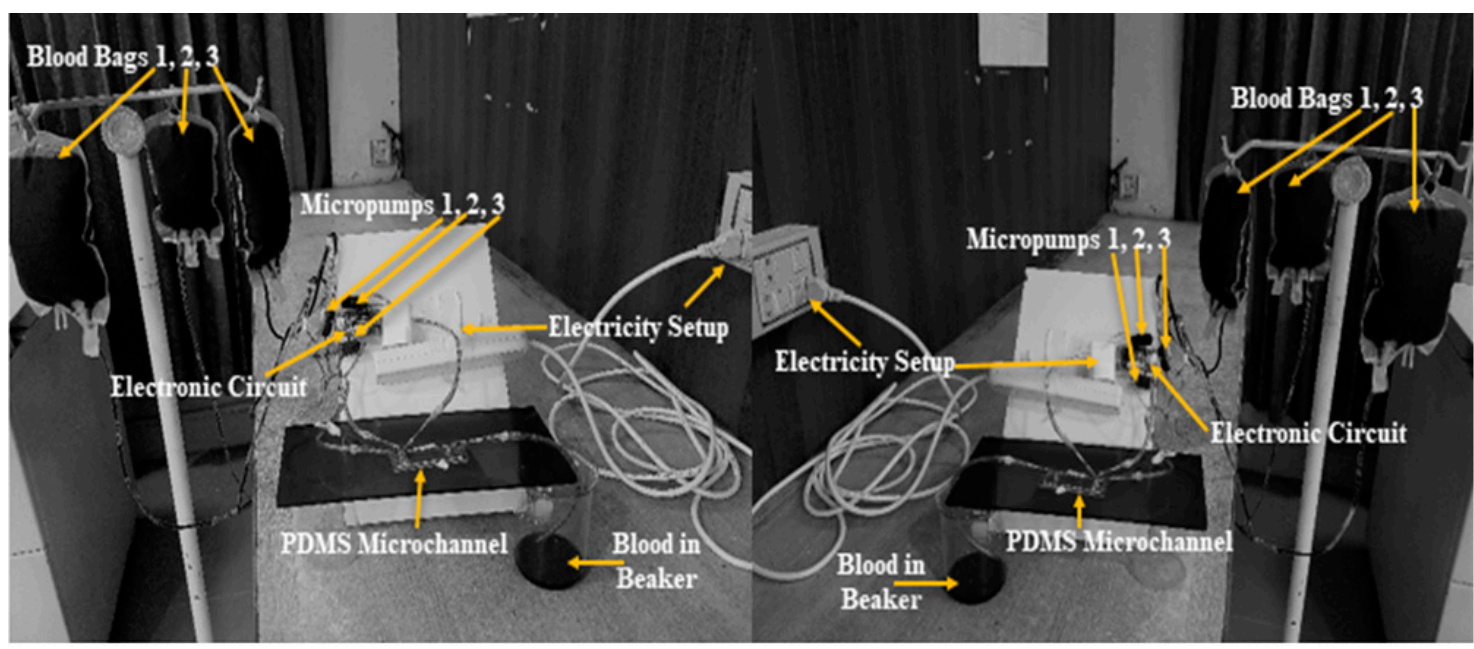

(a)

(b)

Figure 15. Experimental setup (a) 5CACMC (b) 5CDCMC.

The study shows these 5CACMC and 5CDCMC bioengineered vein are suitable for implant. However, it can be investigated further for other parameters and related issues.

\section{Results and Discussion}

The result comparison of MATLAB, ANSYS and experiment for both channels is given in this section. With the rise of the Reynolds number, there is an increase in pressure drop. In this graph Figure 16a, there are two rapid upsurges; one is initially and the other in the middle. The channel has consistent curves with increasing radii. In these curvilinear channels, the fluidic parameters are greater in ascending than in descending channels [81]. 


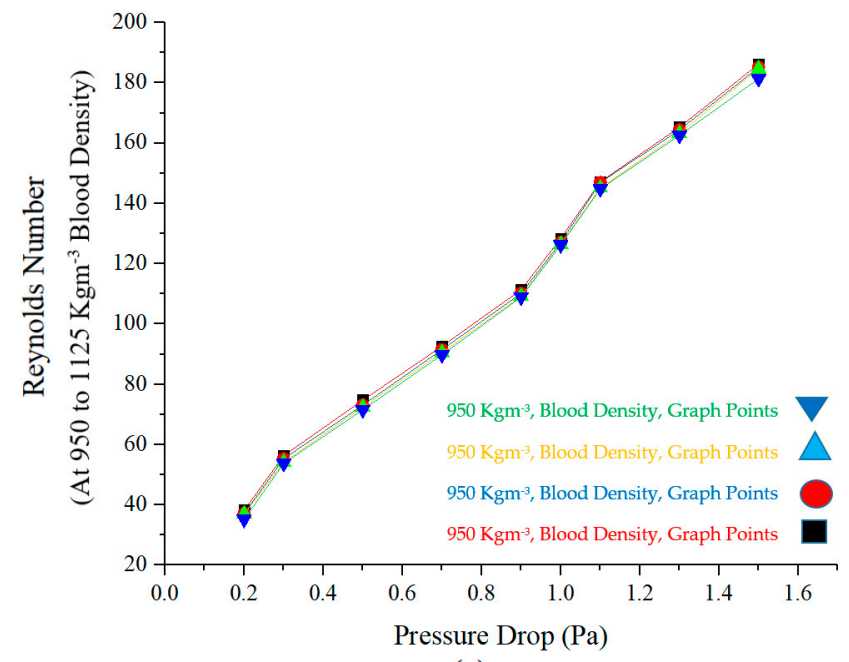

(a)

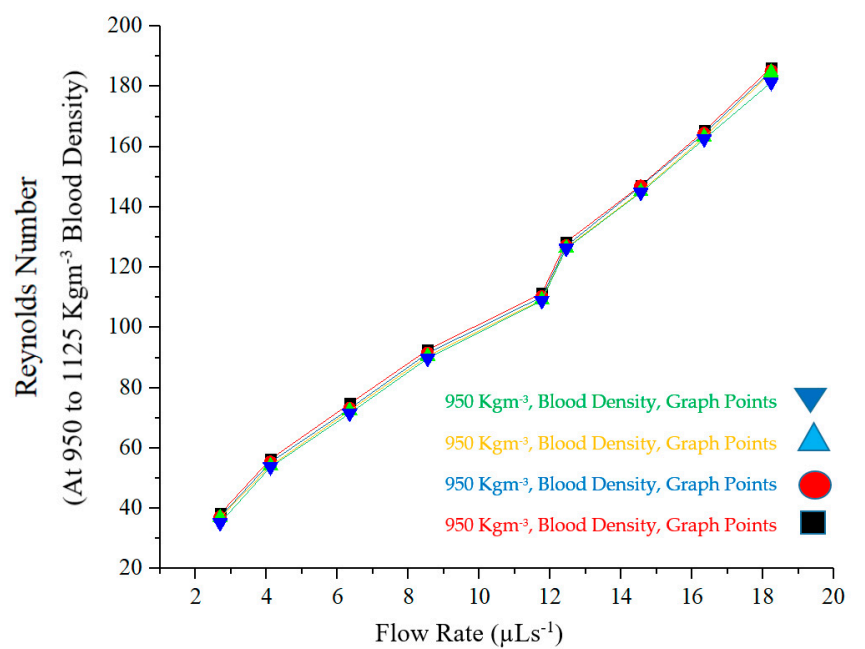

(b)

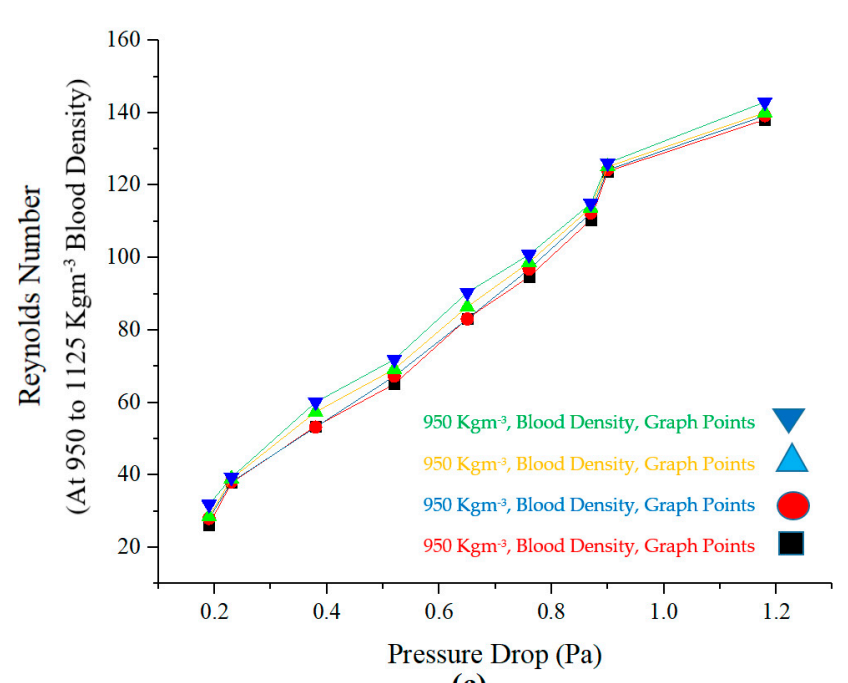

(c)

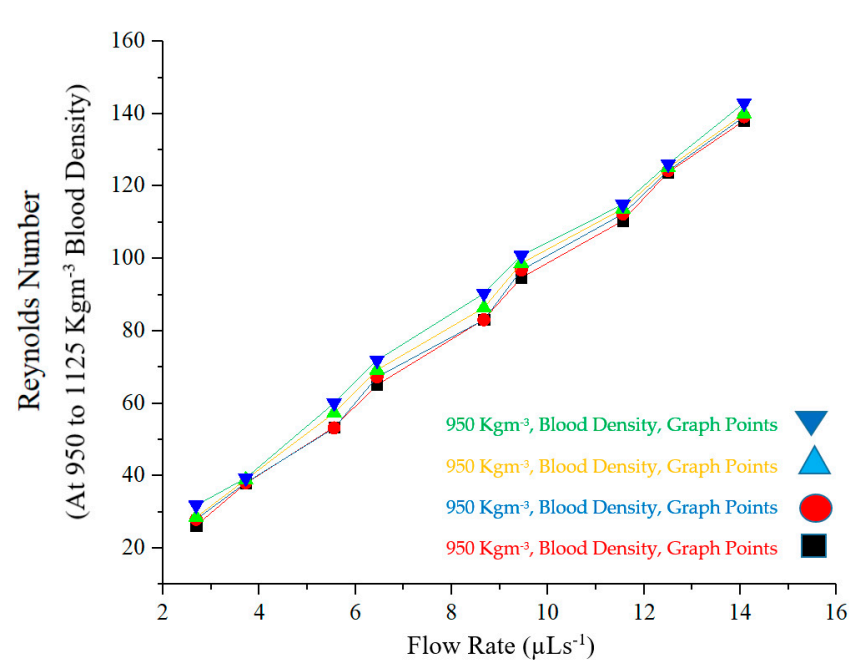

(d)

Figure 16. Experimental graphs (a) Reynolds number and pressure drop for 5CACMC (b) Reynolds number and flow rate for 5CACMC (c) Reynolds number and pressure drop for 5CDCMC (d) Reynolds number and flow rate for 5CDCMC. 
In 5CACMC, the maximum experimental flow rate is $18.23 \mu \mathrm{Ls}^{-1}$. The velocity in this experiment is calculated as $0.1332 \mathrm{~mm} / \mathrm{s}$. The experimental pressure drop in 5CACMC is maximum 1.5 Pa. In 5CDCMC, the maximum experimental flow rate is $14.08 \mu \mathrm{Ls}^{-1}$. The velocity in this experiment is calculated as $0.105 \mathrm{~mm} / \mathrm{s}$, with a pressure drop of $1.18 \mathrm{~Pa}$. All input conditions are the same as in the two simulations for both channels. Pressure drop takes place by increasing resistance inside the veins and acts on blood when it runs through the veins. The main factors of friction to blood flow are blood velocity through the veins, blood viscosity and density. If there is a small blood velocity, then the pressure drop is minimal and vice versa. The values of pressure drop in experiment are 1.5, 1.3, $1.1,1,0.9,0.7,0.5,0.3$ and 0.2 for 5CACMC and 1.18, 0.9, 0.87, 0.76, 0.65, 0.52, 0.38, 0.23 and 0.19 for 5CDCMC. ANSYS fluent simulation shows about the inside pressure of both channels. The values of pressure difference for 5CACMC at blood density $1060 \mathrm{kgm}^{-3}$ were obtained as 2.183, 1.964, 1.746, 1.528, 1.310, 1.091, 0.873, 0.6548, 0.4365 and 0.2183 and for 5CDCMC 373.8, 336.4, 299.1, 261.7, 224.3, 186.9, 149.5, 112.1, 74.76 and 37.38. ANSYS presents higher pressure for the descending channel because of heavy flow. Dean numbers were determined by using the following formulation [82].

$$
D_{e}=R_{e} \sqrt{\frac{d}{2 r}}
$$

The observed Dean numbers for 5CACMC and 5CDCMC are shown in Tables 5 and 6.

Table 5. Dean numbers for 5CACMC.

\begin{tabular}{cccc}
\hline De at $\mathbf{9 5 0} \mathbf{~ K g} / \mathbf{m}^{\mathbf{3}}$ & De at $\mathbf{1 0 0 0} \mathbf{~ K g} / \mathbf{m}^{\mathbf{3}}$ & De at $\mathbf{1 0 6 0} \mathbf{~ K g} / \mathbf{m}^{\mathbf{3}}$ & De at $\mathbf{1 1 2 5} \mathbf{~ K g} / \mathbf{m}^{\mathbf{3}}$ \\
\hline 181.34 & 184.65 & 185.13 & 186.19 \\
\hline 162.57 & 163.24 & 164.39 & 165.24 \\
\hline 144.85 & 145.16 & 146.95 & 147.16 \\
\hline 126.23 & 126.47 & 127.12 & 128.37 \\
\hline 108.91 & 109.25 & 110.19 & 111.35 \\
\hline 89.76 & 90.56 & 91.51 & 92.62 \\
\hline 71.54 & 72.45 & 73.12 & 74.75 \\
\hline 53.78 & 54.17 & 55.34 & 56.37 \\
\hline 35.22 & 36.95 & 37.16 & 38.25 \\
\hline
\end{tabular}

Table 6. Dean numbers for 5CDCMC.

\begin{tabular}{cccc}
\hline De at $\mathbf{9 5 0} \mathbf{~ K g} / \mathbf{m}^{\mathbf{3}}$ & De at $\mathbf{1 0 0 0} \mathbf{~ K g} / \mathbf{m}^{\mathbf{3}}$ & De at $\mathbf{1 0 6 0} \mathbf{~ K g} / \mathbf{m}^{\mathbf{3}}$ & De at $\mathbf{1 1 2 5} \mathbf{~ K g} / \mathbf{m}^{\mathbf{3}}$ \\
\hline 138.11 & 139.19 & 140 & 142.96 \\
\hline 123.82 & 124.26 & 125.12 & 126.12 \\
\hline 110.48 & 112.35 & 113.76 & 114.97 \\
\hline 94.72 & 96.83 & 98.72 & 100.82 \\
\hline 83.21 & 83.11 & 86.44 & 90.38 \\
\hline 65.12 & 67.29 & 69.24 & 71.93 \\
\hline 53.45 & 53.27 & 57.39 & 60.12 \\
\hline 37.93 & 38.11 & 39.01 & 39.39 \\
\hline 26.25 & 27.98 & 28. & 31.88 \\
\hline
\end{tabular}

These Dean numbers are ranging between 35.22 to186.19 for 5CACMC and 26.25 to 142.96 for 5CDCMC. Dean flow cannot be observed due to small Dean numbers [83]. If 
there is Dean flow, then flow must be circular at some turning points [84]. IoT environment provides a purely error-free atmosphere, in which Reynolds Number, time, temperature, pressure and all real-time parameters can be controlled. IoT provided a significant role for biomedical devices and systems [85-87]. The comparison of results is shown below in Table 7. 5CACMC has a higher flow rate, velocity and pressure drop than 5CDCMC. The first reason is the curvilinear nature of the channels. The channels have consistent curves with increasing radii. The second reason is the pressure difference, which is varied inside the channels. Only the ANSYS Fluent can describe the pressure difference inside these channels. The results are in closed agreement with the previously available research [81].

Table 7. Overall Result Comparison.

\begin{tabular}{ccccc}
\hline \multirow{2}{*}{ Channel } & Category & $\begin{array}{c}\text { Fuzzy } \\
\text { Simulation }\end{array}$ & $\begin{array}{c}\text { Fluent } \\
\text { Simulation }\end{array}$ & $\begin{array}{c}\text { Experimental } \\
\text { Values }\end{array}$ \\
\hline \multirow{3}{*}{5 CACMC } & Flow Rate $\left(\mu \mathrm{Ls}^{-1}\right)$ & 19.7 & 19.3 & 18.28 \\
\cline { 2 - 5 } & Velocity $(\mathrm{mm} / \mathrm{s})$ & 0.105 & 0.1543 & 0.1332 \\
\cline { 2 - 5 } & Pressure Drop $(\mathrm{Pa})$ & 1.18 & 1.6 & 1.6 \\
\hline \multirow{3}{*}{$5 \mathrm{CDCMC}$} & Flow Rate $\left(\mu \mathrm{Ls}^{-1}\right)$ & 15.4 & 15.0 & 14.08 \\
\cline { 2 - 5 } & Velocity $(\mathrm{mm} / \mathrm{s})$ & 0.1032 & 0.120 & 0.105 \\
\cline { 2 - 5 } & Pressure Drop $(\mathrm{Pa})$ & 1.15 & 1.22 & 1.22 \\
\hline
\end{tabular}

\section{Conclusions}

The scope of the research is simulations, fabrication and investigations of the biocompatible bioengineered veins for implant in place of varicose veins. The conclusions drawn from this study are given below:

1. Simulation was conducted with the real and natural conditions by MATLAB and ANSYS.

2. After simulated results, the fabrication of 5CACMC and 5CDCMC with PDMS material has been completed.

3. An experimental confirmation has been done for both channels. These bioengineered veins could be inflated and become swollen with blood flow just like healthy veins because of the high flexibility of thin PDMS veins.

4. These channels must be separated from the substrate for the surgical option.

5. The fabricated PDMS microchannels could be a good alternative to varicose veins for good blood flow.

Author Contributions: S.T., M.W.A., Z.A., M.J.A., and N.A. have contributed in Conceptualization, Formal analysis, Funding acquisition, Investigation, Methodology, Project administration, Resources, Software, Supervision, Validation, Visualization, Writing—original draft, Writing—review \& editing. N.W. has contributed in Investigation, Methodology, Project administration, Resources, Software, Supervision, Validation, Visualization, Writing - review \& editing. All authors have read and agreed to the published version of the manuscript.

Funding: The publication of this article was funded by the Qatar National Library.

Conflicts of Interest: The authors declare no conflict of interest.

\section{References}

1. Yuan, Y.; Feng, S.; Alahi, M.E.E.; Nag, A.; Afsarimanesh, N.; Zhang, H.; He, S. Development of an Internet of Things Based Electrochemical Microfluidic System for Free Calcium Detection. Appl. Sci. 2018, 8, 1357. [CrossRef]

2. Mahesh, C.; Arumugam, A.; Kannan, E.; Logesh, K. Atmospheric-temperature-based cooling system control for electronic devices using internet of things. Int. J. Ambient Energy 2020, 41, 112-116. [CrossRef]

3. Narendran, G.; Gnanasekaran, N.; Perumal, D.A. A review on recent advances in microchannel heat sink configurations. Recent Pat. Mech. Eng. 2018, 11, 190-215. [CrossRef] 
4. Dudala, S.; Dubey, S.K.; Goel, S. Microfluidic Soil Nutrient Detection System: Integrating Nitrite, pH and Electrical Conductivity Detection. IEEE Sens. J. 2020, 20, 4504-4511. [CrossRef]

5. Fehring, T.K.; Chaffin, J.H., III; Kennedy, R.L. Enhanced Biocompatible Implants and Alloys. Google Patents US6187045B1, 13 February 2001.

6. Dalle Mura, M.; Dini, G.; Lanzetta, M.; Rossi, A. An Experimental Analysis of Laser Machining for Dental Implants. Procedia CIRP 2018, 67, 356-361. [CrossRef]

7. Kheir, J.N.; Leslie, L.F.; Fulmer, N.L.; Edlich, R.F.; Gampper, T.J. Polydimethylsiloxane for augmentation of the chin, malar, and nasal bones. J. Long-Term Eff. Med. Implant. 1998, 8, 55-67.

8. Ashraf, M.W.; Tayyaba, S.; Afzulpurkar, N.; Nisar, A. Fabrication and analysis of tapered tip silicon microneedles for mems based drug delivery system. Sens. Transducers 2010, 122, 158.

9. Ashraf, M.W.; Tayyaba, S.; Afzulpurkar, N.; Nisar, A.; Bohez, E.L.; Tuantranont, A. Structural and microfluidic analysis of MEMS based out-of-plane hollow silicon microneedle array for drug delivery. In Proceedings of the 2010 IEEE Conference on Automation Science and Engineering (CASE), Toronto, ON, Canada, 21-24 August 2010; pp. 258-262.

10. Tayyaba, S.; Ashraf, M.W.; Afzulpurkar, N. Simulation and fabrication of blood filtration system for patients with kidney diseases. IET Commun. 2012, 6, 3213-3221. [CrossRef]

11. Tayyaba, S.; Ashraf, M.W.; Khan, M.S.; Afzulpurkar, N.; Imran, M. Sinusoidal Microchannel Simulation for Cell Sorting System. Bahria Univ. J. Inf. Commun. Technol. 2013, 6, 37.

12. Afzal, M.J.; Tayyaba, S.; Ashraf, M.W.; Sarwar, G. Simulation of fuzzy based flow controller in ascending sinusoidal microchannels. In Proceedings of the 2016 2nd International Conference on Robotics and Artificial Intelligence (ICRAI), Rawalpindi, Pakistan, 1-2 November 2016; pp. 141-146.

13. Hanabusa, K.; Nakashima, M.; Funatsu, E.; Kishi, S.; Suzuki, M. A Safe, Simple, and Facile Staining Method Using Polysiloxanes for High-Contrast Visualization of Gelator Aggregates by Transmission Electron Microscopy. Bull. Chem. Soc. Jpn. 2018, 91, 1176-1185. [CrossRef]

14. Chen, J.; Fine, J.D.; Mullin, C.A. Are organosilicon surfactants safe for bees or humans? Sci. Total Environ. 2018, 612, 415-421. [CrossRef]

15. Norfatriah, A.; Syamaizar, A.S.A.; Zuruzi, A.S. Application of Porous Polydimethylsiloxane (PDMS) in oil absorption. In Proceedings of the IOP Conference Series: Materials Science and Engineering, Pekan, Malaysia, 1-2 March $2018 ;$ p. 012050.

16. Liu, C.; Zhang, Q.; Wang, D.; Zhao, G.; Cai, X.; Li, L.; Ding, H.; Zhang, K.; Wang, H.; Kong, D. High Performance, Biocompatible Dielectric Thin-Film Optical Filters Integrated with Flexible Substrates and Microscale Optoelectronic Devices. Adv. Opt. Mater. 2018, 6, 1800146. [CrossRef]

17. Stevens, M.M. Biomaterials for bone tissue engineering. Mater. Today 2008, 11, 18-25. [CrossRef]

18. Hastings, G. Biomaterials and artificial organs: Royal College of Surgeons, London, 7 March 1980. Med. Eng. Phys. 1980, 2, 229-230.

19. Burg, K.J.; Porter, S.; Kellam, J.F. Biomaterial developments for bone tissue engineering. Biomaterials 2000, 21, $2347-2359$. [CrossRef]

20. Rahman, N.A.A.; Matori, K.A.; Zaid, M.H.M.; Zainuddin, N.; Ab Aziz, S.; Khiri, M.Z.A.; Jalil, R.A.; Jusoh, W.N.W. Fabrication of Alumino-Silicate-Fluoride based bioglass derived from waste clam shell and soda lime silica glasses. Results Phys. 2019, 12, 743-747. [CrossRef]

21. Pocivavsek, L.; Ye, S.H.; Pugar, J.; Tzeng, E.; Cerda, E.; Velankar, S.; Wagner, W.R. Active wrinkles to drive self-cleaning: A strategy for anti-thrombotic surfaces for vascular grafts. Biomaterials 2019, 192, 226-234. [CrossRef]

22. Kim, H.S.; Kim, D.Y.; Kwak, J.H.; Kim, J.H.; Choi, M.; Kim, D.H.; Lee, D.W.; Kong, D.S.; Park, J.; Jung, S. Microwave-welded single-walled carbon nanotubes as suitable electrodes for triboelectric energy harvesting from biomaterials and bioproducts. Nano Energy 2019, 56, 338-346. [CrossRef]

23. Middleton, J.C.; Tipton, A.J. Synthetic biodegradable polymers as orthopedic devices. Biomaterials 2000, 21, 2335-2346. [CrossRef]

24. Fang, J.; Fowler, P.; Escrig, C.; Gonzalez, R.; Costa, J.; Chamudis, L. Development of biodegradable laminate films derived from naturally occurring carbohydrate polymers. Carbohydr. Polym. 2005, 60, 39-42. [CrossRef]

25. Costoya, A.; Becerra, L.E.V.; Meléndez-Ortiz, H.I.; Díaz-Gómez, L.; Mayer, C.; Otero, A.; Concheiro, A.; Bucio, E.; Alvarez-Lorenzo, C. Immobilization of antimicrobial and anti-quorum sensing enzymes onto GMA-grafted poly (vinyl chloride) catheters. Int. J. Pharm. 2019, 558, 72-81. [CrossRef]

26. Ramachandran, B.; Chakraborty, S.; Kannan, R.; Dixit, M.; Muthuvijayan, V. Immobilization of hyaluronic acid from Lactococcus lactis on polyethylene terephthalate for improved biocompatibility and drug release. Carbohydr. Polym. 2019, 206, 132-140. [CrossRef]

27. Orenstein, S.B. Permanent Prosthetics: Polypropylene, Polyester, ePTFE, and Hybrid Mesh. In The SAGES Manual of Hernia Surgery; Springer: Berlin/Heidelberg, Germany, 2019; pp. 57-69.

28. Caplin, J.D.; García, A.J. Implantable Antimicrobial Biomaterials for Local Drug Delivery in Bone Infection Models. Acta Biomater. 2019, 93, 2-11. [CrossRef]

29. Sefat, F.; Raja, T.I.; Moghadam, Z.S.; Milan, P.B.; Samadikuchaksaraei, A.; Mozafari, M. Nanoengineered biomaterials for bladder regeneration. In Nanoengineered Biomaterials for Regenerative Medicine; Elsevier: Berlin/Heidelberg, Germany, 2019 ; pp. 459-474. 
30. Navaei, T.; Milan, P.B.; Davari, H.R.; Samadikuchaksaraei, A.; Mozafari, M. Nanoengineered biomaterials for diaphragm regeneration. In Nanoengineered Biomaterials for Regenerative Medicine; Elsevier: Berlin/Heidelberg, Germany, 2019 ; pp. 345-362.

31. Oran, D.C.; Gokulu, I.S.; Kizilel, S. Nanoengineered biomaterials for pancreas regeneration. In Nanoengineered Biomaterials for Regenerative Medicine; Elsevier: Berlin/Heidelberg, Germany, 2019; pp. 443-457.

32. Zhao, W.; He, B.; Zhou, A.; Li, Y.; Chen, X.; Yang, Q.; Chen, B.; Qiao, B.; Jiang, D. D-RADA16-RGD-Reinforced NanoHydroxyapatite/Polyamide 66 Ternary Biomaterial for Bone Formation. Tissue Eng. Regen. Med. 2019, 16, 177-189. [CrossRef]

33. Zhu, Y.; Wagner, W.R. Design Principles in Biomaterials and Scaffolds. In Principles of Regenerative Medicine; Elsevier: Berlin/Heidelberg, Germany, 2019; pp. 505-522.

34. Ji, M.; Chen, X.; Luo, J.; Wan, Y. Improved blood compatibility of polysulfone membrane by anticoagulant protein immobilization. Colloids Surf. B Biointerfaces 2019, 175, 586-595. [CrossRef]

35. Sun, T.; Guo, X.; Zhong, R.; Ma, L.; Li, H.; Gu, Z.; Guan, J.; Tan, H.; You, C.; Tian, M. Interactions of oligochitosan with blood components. Int. J. Biol. Macromol. 2019, 124, 304-313. [CrossRef]

36. Hannula, M.; Narra, N.; Paakinaho, K.; Haaparanta, A.M.; Kellomäki, M.; Hyttinen, J. $\mu$ CT Based Characterization of Biomaterial Scaffold Microstructure Under Compression. In Proceedings of the World Congress on Medical Physics and Biomedical Engineering, Prague, Czech Republic, 3-8 June 2018; pp. 165-169.

37. Zhang, C.; Yuan, Y.; Fang, L.; Xuan, Y. Promotion of osteogenesis by bioactive glass-ceramic coating: Possible involvement of the Hedgehog signaling pathway. J. Orthop. Sci. 2019, 24, 731-736. [CrossRef]

38. Nate, K.; Tentzeris, M.M. A novel 3-D printed loop antenna using flexible NinjaFlex material for wearable and IoT applications. In Proceedings of the 2015 IEEE 24th Electrical Performance of Electronic Packaging and Systems (EPEPS), San Jose, CA, USA, 25-28 October 2015; pp. 171-174.

39. Paracha, K.N.; Butt, A.D.; Alghamdi, A.S.; Babale, S.A.; Soh, P.J. Liquid Metal Antennas: Materials, Fabrication and Applications. Sensors 2020, 20, 177. [CrossRef]

40. He, S.; Feng, S.; Nag, A.; Afsarimanesh, N.; Han, T.; Mukhopadhyay, S.C. Recent Progress in 3D Printed Mold-Based Sensors. Sensors 2020, 20, 703. [CrossRef]

41. Langer, K.; Jönsson, H. DRAFT-Robotic automation of production and the recovery of cell spheroids. BioRxiv 2019, 552687. [CrossRef]

42. Afzal, M.J.; Tayyaba, S.; Ashraf, M.W.; Hossain, M.K.; Uddin, M.J.; Afzulpurkar, N. Simulation, Fabrication and Analysis of Silver Based Ascending Sinusoidal Microchannel (ASMC) for Implant of Varicose Veins. Micromachines 2017, 8, 278. [CrossRef]

43. Afzal, M.J.; Ashraf, M.W.; Tayyaba, S.; Hossain, M.K.; Afzulpurkar, N. Sinusoidal Microchannel with Descending Curves for Varicose Veins Implantation. Micromachines 2018, 9, 59. [CrossRef]

44. Morent, R.; De Geyter, N.; Axisa, F.; De Smet, N.; Gengembre, L.; De Leersnyder, E.; Leys, C.; Vanfleteren, J.; Rymarczyk-Machal, M.; Schacht, E. Adhesion enhancement by a dielectric barrier discharge of PDMS used for flexible and stretchable electronics. J. Phys. D Appl. Phys. 2007, 40, 7392. [CrossRef]

45. Cong, H.; Pan, T. Microfabrication of conductive PDMS on flexible substrates for biomedical applications. In Proceedings of the 2009 4th IEEE International Conference on Nano/Micro Engineered and Molecular Systems, Shenzhen, China, 5-8 January 2009.

46. Zhao, B.; Moore, J.S.; Beebe, D.J. Pressure-sensitive microfluidic gates fabricated by patterning surface free energies inside microchannels. Langmuir 2003, 19, 1873-1879. [CrossRef]

47. Pinho, D.; Lima, R.; Pereira, A.I.; Gayubo, F. Automatic tracking of labeled red blood cells in microchannels. Int. J. Numer. Methods Biomed. Eng. 2013, 29, 977-987. [CrossRef]

48. Chang, L.; Howdyshell, M.; Liao, W.C.; Chiang, C.L.; Gallego-Perez, D.; Yang, Z.; Lu, W.; Byrd, J.C.; Muthusamy, N.; Lee, L.J.; et al. Magnetic Tweezers-Based 3D Microchannel Electroporation for High-Throughput Gene Transfection in Living Cells. Small 2015, 11, 1818-1828. [CrossRef]

49. Chen, C.H.; Lu, Y.; Sin, M.L.; Mach, K.E.; Zhang, D.D.; Gau, V.; Liao, J.C.; Wong, P.K. Antimicrobial susceptibility testing using high surface-to-volume ratio microchannels. Anal. Chem. 2010, 82, 1012-1019. [CrossRef]

50. Li, J. Computational Analysis of Nanofluid Flow in Microchannels with Applications to Micro-Heat Sinks and bio-MEMS. Ph.D. Thesis, North Carolina State University, Raleigh, NC, USA, 2008.

51. Laporte, M.; Montillet, A.; Belkadi, A.; Della Valle, D.; Loisel, C.; Riaublanc, A.; Hauser, J. Investigation of gas/shear-thinning liquids flow at high throughput in microchannels with the aim of producing biosourced foam. Chem. Eng. Process. Process Intensif. 2020, 148, 107787. [CrossRef]

52. Perkins, J.J.; Perkins, B.J.J. Principles and Methods of Sterilization in Health Sciences; Academic Press Inc.: London, UK, 1969.

53. White, L.J.; Keane, T.J.; Smoulder, A.; Zhang, L.; Castleton, A.A.; Reing, J.E.; Turner, N.J.; Dearth, C.L.; Badylak, S.F. The impact of sterilization upon extracellular matrix hydrogel structure and function. J. Immunol. Regen. Med. 2018, 2, 11-20. [CrossRef]

54. Tipnis, N.P.; Burgess, D.J. Sterilization of implantable polymer-based medical devices: A review. Int. J. Pharm. 2018, 544, 455-460. [CrossRef]

55. Laurencin, C.; Pierre-Jacques, H.; Langer, R. Toxicology and biocompatibility considerations in the evaluation of polymeric materials for biomedical applications. Clin. Lab. Med. 1990, 10, 549-570.

56. Kim, S.H.; Moon, J.H.; Kim, J.H.; Jeong, S.M.; Lee, S.H. Flexible, stretchable and implantable PDMS encapsulated cable for implantable medical device. Biomed. Eng. Lett. 2011, 1, 199. [CrossRef] 
57. Teo, A.J.; Mishra, A.; Park, I.; Kim, Y.J.; Park, W.T.; Yoon, Y.J. Polymeric biomaterials for medical implants and devices. ACS Biomater. Sci. Eng. 2016, 2, 454-472. [CrossRef]

58. Petrovskaya, T.; Toropkov, N.; Mironov, E.; Azarmi, F. 3D printed biocompatible polylactidehydroxyapatite based material for bone implants. Mater. Manuf. Process. 2018, 33, 1899-1904. [CrossRef]

59. Colucci, F.; McKeegan, P.; Picton, H.; Pensabene, V. Mouse embryo assay to evaluate polydimethylsiloxane (PDMS) embryotoxicity. In Proceedings of the IEEE 40th Annual International Conference of the Engineering in Medicine and Biology Society (EMBC 2018), Honolulu, Hawaii, 17-21 July 2018.

60. Siproudhis, L.; Morcet, J.; Laine, F. Elastomer implants in faecal incontinence: A blind, randomized placebo-controlled study. Aliment. Pharmacol. Ther. 2007, 25, 1125-1132. [CrossRef]

61. Losi, P.; Munaò, A.; Spiller, D.; Briganti, E.; Martinelli, I.; Scoccianti, M.; Soldani, G. Evaluation of a new composite prosthesis for the repair of abdominal wall defects. J. Mater. Sci. Mater. Med. 2007, 18, 1939-1944. [CrossRef]

62. Tunc, M.; Humayun, M.; Cheng, X.; Ratner, B.D. A reversible thermosensitive adhesive for retinal implants: In vivo experience with plasma-deposited poly (N-isopropyl acrylamide). Retina 2008, 28, 1338-1343. [CrossRef]

63. Kuo, C.K.; Marturano, J.E.; Tuan, R.S. Novel strategies in tendon and ligament tissue engineering: Advanced biomaterials and regeneration motifs. BMC Sports Sci. Med. Rehabil. 2010, 2, 20. [CrossRef]

64. Defrere, S.; Mestagdt, M.; Riva, R.; Krier, F.; van Langendonckt, A.; Drion, P.; Jerome, C.; Evrard, B.; Dehoux, J.; Foidart, J.; et al. In vivo biocompatibility of three potential intraperitoneal implants. Macromol. Biosci. 2011, 11, 1336-1345. [CrossRef]

65. França, D.C.C.; de Castro, A.L.; Soubhia, A.M.P. Evaluation of the Biocompatibility of Silicone Gel Implants-Histomorphometric Study. Acta Inform. Med. 2013, 21, 93. [CrossRef]

66. Suchý, T.; Rýglová, Š.; Balík, K.; Smetana, K.; Šupová, M.; Sucharda, Z.; Filová, E.; Havlíková, J.; Bačáková, L.; Martynková, G.S. Biological evaluation of polydimethylsiloxane modified by calcium phosphate nanoparticles for potential application in spine surgery. Sci. Adv. Mater. 2013, 5, 484-493. [CrossRef]

67. Lim, E.H.; Sardinha, J.P.; Myers, S. Nanotechnology biomimetic cartilage regenerative scaffolds. Arch. Plast. Surg. 2014, 41, 231. [CrossRef]

68. Singh, J.; Inaty, H.; Mukhopadhyay, S.; Mehta, A.C. Chronic Pulmonary Silicone Embolism from Breast Augmentation Is Not a Common Finding in Explanted Lungs. Pulm. Med. 2018, 2018, 1-5. [CrossRef]

69. Zhang, B.; Lai, B.F.L.; Xie, R.; Huyer, L.D.; Montgomery, M.; Radisic, M. Microfabrication of AngioChip, a biodegradable polymer scaffold with microfluidic vasculature. Nat. Protoc. 2018, 13, 1793-1813. [CrossRef]

70. Holmes, G. Augmented Reality Assisted Orthopaedic Surgery. Master's Thesis, Stellenbosch University, Stellenbosch, South Africa, 2018.

71. Merrill, E.W.; Pelletier, G.A. Viscosity of human blood: Transition from Newtonian to non-Newtonian. J. Appl. Physiol. 1967, 23, 178-182. [CrossRef]

72. Athanasiou, K.A.; Niederauer, G.G.; Agrawal, C.M. Sterilization, toxicity, biocompatibility and clinical applications of polylactic acid/polyglycolic acid copolymers. Biomaterials 1996, 17, 93-102. [CrossRef]

73. Tayyaba, S.; Afzal, M.J.; Sarwar, G.; Ashraf, M.W.; Afzulpurkar, N. Simulation of flow control in straight microchannels using fuzzy logic. In Proceedings of the 2016 International Conference on Computing, Electronic and Electrical Engineering (ICE Cube), Quetta, Pakistan, 11-12 April 2016; pp. 213-216.

74. Afzal, M.J.; Javaid, F.; Tayyaba, S.; Ashraf, M.W.; Ashiq, M.; Akhtar, A. Simulation of a Nanoneedle for Drug Delivery by Using MATLAB Fuzzy Logic. Biologia 2018, 64, 75.

75. Afzal, M.J.; Javaid, F.; Tayyaba, S.; Ashraf, M.W.; Punyasai, C.; Afzulpurkar, N. Study of Charging the Smart Phone by Human Movements by Using MATLAB Fuzzy Technique. In Proceedings of the 2018 15th International Conference on Electrical Engineering/Electronics, Computer, Telecommunications and Information Technology (ECTI-CON), Nakhonpathom, Thailand, 11-13 July 2018; pp. 411-414.

76. Afzal, M.J.; Javaid, F.; Tayyaba, S.; Sabah, A.; Ashraf, M.W. Fluidic simulation for blood flow in five curved Spiral Microchannel. Biologia 2019, 65, 1 .

77. Ashraf, M.; Tayyaba, S.; Nisar, A.; Afzulpurkar, N.; Bodhale, D.; Lomas, T.; Poyai, A.; Tuantranont, A. Design, fabrication and analysis of silicon hollow microneedles for transdermal drug delivery system for treatment of hemodynamic dysfunctions. Cardiovasc. Eng. 2010, 10, 91-108. [CrossRef]

78. Sivanandam, S.; Sumathi, S.; Deepa, S. Introduction to Fuzzy Logic Using MATLAB; Springer: Berlin/Heidelberg, Germany, 2007; Volume 1.

79. Afzal, M.J.; Tayyaba, S.; Ashraf, M.W.; Hossain, M.K.; Afzulpurkar, N. Fluidic simulation and analysis of spiral, U-shape and curvilinear nano channels for biomedical application. In Proceedings of the 2017 IEEE International Conference on Manipulation, Manufacturing and Measurement on the Nanoscale (3M-NANO), Shanghai, China, 7-11 August 2017; pp. $190-194$.

80. Martinez, R.; Fierro, C.A.; Shireman, P.K.; Han, H.C. Mechanical buckling of veins under internal pressure. Ann. Biomed. Eng. 2010, 38, 1345-1353. [CrossRef] [PubMed]

81. Wewala, W.; Kasi, J.K.; Kasi, A.K.; Afzulpurkar, N. Design, simulation and comparison of ascending and descending curvilinear microchannels for cancer cell separation from blood. Biomed. Eng. Appl. Basis Commun. 2013, 25, 1350037. [CrossRef]

82. Germano, M. The Dean equations extended to a helical pipe flow. J. Fluid Mech. 1989, 203, 289-305. [CrossRef] 
83. Dean, W. LXXII. The stream-line motion of fluid in a curved pipe (Second paper). Lond. Edinb. Dublin Philos. Mag. J. Sci. 1928, 5, 673-695. [CrossRef]

84. Storbeck, G.T.; Hingston, J.A.; Merkling, S.M.; Hiller, J.A.; Corcoran, K.; Manning, K.L.; Roye, G.D.; Vithiananthan, S.; Ryder, B. Devices and Methods for Modulating Intestinal Flow. Google Patents US 2018/0110641 A1, 26 April 2018.

85. Aktas, F.; Ceken, C.; Erdemli, Y.E. IoT-based healthcare framework for biomedical applications. J. Med. Biol. Eng. 2018, 38, 966-979. [CrossRef]

86. Kim, T.; Im, D.; Kwon, K. 360- $\mu$ W 4.1-dB NF CMOS MedRadio receiver RF front-end with current-reuse Q-boosted resistive feedback LNA for biomedical IoT applications. Int. J. Circuit Theory Appl. 2020. [CrossRef]

87. Zagan, I.; Găitan, V.G.; Petrariu, A.I.; Iuga, N.; Brezulianu, A. Design, Fabrication, and Testing of an IoT Healthcare Cardiac Monitoring Device. Computers 2020, 9, 15. [CrossRef] 